\title{
Pulmonary endothelial cell DNA methylation signature in pulmonary arterial hypertension
}

\author{
Aurélie Hautefort ${ }^{1,2, *}$, Julie Chesné ${ }^{3, *}, J^{2}$ Jens Preussner ${ }^{4}$, Soni S Pullamsetti ${ }^{4}$, Jorg \\ Tost $^{5}$, Mario Looso ${ }^{4}$, Fabrice Antigny ${ }^{1,2}$, Barbara Girerd ${ }^{1,2,6}$, Marianne Riou ${ }^{1,2}$, \\ Saadia Eddahibi', Jean-François Deleuze ${ }^{5}$, Werner Seeger ${ }^{4}$, Elie Fadel ${ }^{8}$, Gerald \\ Simonneau ${ }^{1,2,6}$, David Montani ${ }^{1,2,6}$, Marc Humbert ${ }^{1,2,6}$ and Frédéric Perros ${ }^{1,2}$ \\ ${ }^{1}$ INSERM UMR_S 999, Hôpital Marie Lannelongue, Le Plessis Robinson, France \\ ${ }^{2}$ Univ Paris-Sud, Faculté de Médecine, Université Paris-Saclay, Le Kremlin Bicêtre, France \\ 33MR_S 1087 CNRS UMR_6291, Institut du Thorax, Université de Nantes, CHU de Nantes, Centre National de Référence \\ Mucoviscidose Nantes-Roscoff, Nantes, France \\ ${ }^{4}$ Max-Planck-Institute for Heart and Lung Research, Member of the German Center for Lung Research (DZL), Bad Nauheim, \\ Germany \\ ${ }^{5}$ Centre National de Génotypage, CEA-Institut de Génomique, Evry, France \\ ${ }^{6}$ AP-HP, Service de Pneumologie, Hôpital Bicêtre, Le Kremlin-Bicêtre, France \\ ${ }^{7}$ INSERM U1046, Centre Hospitalier Universitaire Arnaud de Villeneuve, Montpellier, France \\ ${ }^{8}$ Hôpital Marie Lannelongue, Service de Chirurgie Thoracique et Vasculaire, Le Plessis Robinson, France \\ *These authors contributed equally to this work
}

Correspondence to: Frédéric Perros, email: frederic.perros@inserm.fr

Keywords: pulmonary arterial hypertension, epigenetic, DNA methylation, endothelial cells, ABC transporters

Received: December 02, $2016 \quad$ Accepted: May 09, $2017 \quad$ Published: May 19, 2017

Copyright: Hautefort et al. This is an open-access article distributed under the terms of the Creative Commons Attribution License 3.0 (CC BY 3.0), which permits unrestricted use, distribution, and reproduction in any medium, provided the original author and source are credited.

\section{ABSTRACT}

Pulmonary arterial hypertension (PAH) is a severe and incurable pulmonary vascular disease. One of the primary origins of PAH is pulmonary endothelial dysfunction leading to vasoconstriction, aberrant angiogenesis and smooth muscle cell proliferation, endothelial-to-mesenchymal transition, thrombosis and inflammation. Our objective was to study the epigenetic variations in pulmonary endothelial cells (PEC) through a specific pattern of DNA methylation.

DNA was extracted from cultured PEC from idiopathic PAH $(n=11)$, heritable PAH $(n=10)$ and controls $(n=18)$. DNA methylation was assessed using the Illumina HumanMethylation450 Assay. After normalization, samples and probes were clustered according to their methylation profile. Differential clusters were functionally analyzed using bioinformatics tools.

Unsupervised hierarchical clustering allowed the identification of two clusters of probes that discriminates controls and PAH patients. Among 147 differential methylated promoters, 46 promoters coding for proteins or miRNAs were related to lipid metabolism. Top 10 up and down-regulated genes were involved in lipid transport including ABCA1, ABCB4, ADIPOQ, miR-26A, BCL2L11. NextBio metaanalysis suggested a contribution of ABCA1 in PAH. We confirmed ABCA1 mRNA and protein downregulation specifically in PAH PEC by qPCR and immunohistochemistry and made the proof-of-concept in an experimental model of the disease that its targeting may offer novel therapeutic options.

In conclusion, DNA methylation analysis identifies a set of genes mainly involved in lipid transport pathway which could be relevant to PAH pathophysiology. 


\section{INTRODUCTION}

Pulmonary arterial hypertension (PAH) is a rare and severe condition defined by right heart catheterization as precapillary pulmonary hypertension (mean pulmonary arterial pressure $\geq 25 \mathrm{mmHg}$ and pulmonary artery wedge pressure $\leq 15 \mathrm{mmHg}$ ), in the absence of other causes such as chronic thromboembolic pulmonary disease or chronic respiratory diseases and/or hypoxia [1]. PAH is the consequence of the progressive narrowing of the pulmonary precapillary vasculature that increases pulmonary vascular resistance. Pulmonary endothelial cell (PEC) dysfunction is a major player of PAH pathobiology. It is characterized by 1) PEC barrier breakdown, endothelial-to-mesenchymal transition and subsequent neointima formation [2], 2) pulmonary arterial vasoconstriction and remodeling through paracrine production of potent vasoconstrictors and growth factors that induce the contraction and the proliferation of underlying pulmonary arterial smooth muscle cells (PASMC) (medial hypertrophy) [3], pulmonary vascular inflammation [4], and in situ thrombosis [5]. Currently approved PAH therapies are all targeting three major PEC dysfunctional pathways involved in the abnormal PEC-PASMC crosstalk [6]. However none are curative, prompting the need of targeting other pathological signaling pathways in the future management of PAH.

We aimed at discovering genes, groups of coregulated genes or pathways that would be differentially regulated in PAH and responsible for PEC dysfunction. Gene expression profiles are dependent on changes in the epigenome, including DNA methylation, histone modifications, and noncoding RNA regulation. DNA methylation is one of the most stable epigenetic modifications and traditionally regarded as the major mediator of epigenetic regulation. DNA methylation usually occurs at clusters of $\mathrm{CpG}$ dinucleotides called $\mathrm{CpG}$ islands, generally in promoter regions, often associated with the transcriptional inactivation of the affected gene [7]. DNA methylation contributes to the pathogenesis of pulmonary diseases, such as cancer, chronic obstructive pulmonary disease, and idiopathic pulmonary fibrosis $[8,9]$. Two hypothesis-driven studies have already demonstrated methylation alterations in the genes coding for the superoxide dismutase 2 (SOD2) [10] and granulysin [11] in pulmonary hypertension $(\mathrm{PH})$. However, studies examining DNA methylation on a global scale in PAH are lacking [12].

mRNA-based expression profile is the result of nutritional, growth factors, cytokines, neuro-hormonal stimulation present in the culture medium, and is also the result of the duration, the amplitude of these stimulations, and the combination of both at a certain time point of the life and of the cycle of the cell. Thus, mRNA-based expression profile is highly variable according to culture conditions. We hypothesized that stable and long-lasting
DNA-based methylation profile represent the propensity for genes and groups of genes to be expressed or not, and that the sum of these propensities makes the ground for PEC dysfunction and PAH predisposition.

In this work, we provide for the first time a map of DNA methylation-based epigenetic predispositions to $\mathrm{PAH}$, in isolated and cultured PEC. We have identified two signatures specific of PAH containing hypo-methylated and hyper-methylated promoters. A combination of bioinformatic tools was applied to determine the biological annotations of each pattern. We identified ABCA1 downregulation as one of the central hubs within the pathobiological networks responsible for PAH-related PEC dysfunction. We confirmed its mRNA and protein downregulation specifically in $\mathrm{PAH}$ PEC by qPCR and immunohistochemistry and made the proof-of-concept in experimental model of the disease that its targeting may offer novel therapeutic options.

\section{RESULTS}

\section{Methylation profiling of PEC from PAH patients reveals two differential methylated signatures}

DNA methylation assays were performed on cultured PEC from patients with PAH (11 idiopathic and 10 heritable) and 18 controls. Significant differentially methylated promoter regions were detected by ADMIRE and filtered using a FDR $<0.05$ for each group (control versus idiopathic PAH; control vs heritable $\mathrm{PAH}$ and control vs idiopathic PAH and heritable PAH). We then used an unsupervised clustering approach to select signatures containing the most hyper- or hypo-methylated regions (Figure 1A). Among 4076 differentially methylated probes between control and PAH patients (idiopathic and heritable PAH), 726 (cluster 1) and 253 (cluster 2) probes discriminated both groups and corresponded to 352 hyper-methylated and 84 hypomethylated promoters, respectively. Interestingly, only three promoters were differentially methylated between IPAH and HPAH patients suggesting that these patients present a similar methylation profile in their PEC despite different aetiologies (Figure 2A). We also generated a 2D plot (Principal Component Analysis (PCA) of the methylation profile (promoters) of IPAH and HPAH patients) to compare whole methylations between both populations, together with the calculation of Pearson's correlation coefficient. The PCA analysis confirmed that methylation pattern is similar between hPAH and iPAH (Figure 2B). The Pearson correlation values was calculated between the mean of all $\mathrm{CpG}$ sites in promoters from hPAH and from iPAH. The coefficient is 0,9957 which is high because the vast majority of the $\mathrm{CpG}$ sites do not change between hPAH and PAH and those dominate the correlation. To rule out confounding factors, we additionally plotted the age and the gender showing no specific association to a cluster (Figure 1A). 
Using N2C, we performed a functional analysis on a compiled list of hyper-methylated (cluster $1, n=$ 237) and hypo-methylated (cluster 2, $n=47$ ) promoters coding for proteins (Figure 1B). This application allowed us to create canvases with enriched terms highlighted $(p$-value $<0.05)$ from 4 gene-set libraries (see method section). A part of the promoters discriminating PAH patients and controls is related to cardiomyopathy diseases with roles in cardiac muscle contraction and cardiac muscle morphogenesis (Figure 1B, Tables 1-3). Among them, promoters regulating DES (Desmin), ETS2 (ETS Proto-Oncogene 2, Transcription Factor), TBX1/5 (T-box 1/5), TERT (Telomerase Reverse Transcriptase) or MYH7 (Myosine $\beta$ ) were the most represented genes. In addition, we identified promoters involved in inflammatory process known to have a major role in PAH including ZAP70 (SykRelated Tyrosine Kinase), STAT5A (Signal Transducer and Activator of Transcription 5A), COL1A1 (Alpha-1 Type I Collagen) and TNFSF4 (Tumor Necrosis Factor Superfamily Member 4) (Figure 1B, Tables 2 and 3). Interestingly, significant differential methylation was also found in gene promoters related to lipid transport activities such as ABCA1 (ATP-binding cassette 1), ADIPOQ (Adiponectin) and APOA4 (Apolipoprotein A4) (Figure 1B, Tables 2 and 3).

A. Unsupervised clustering

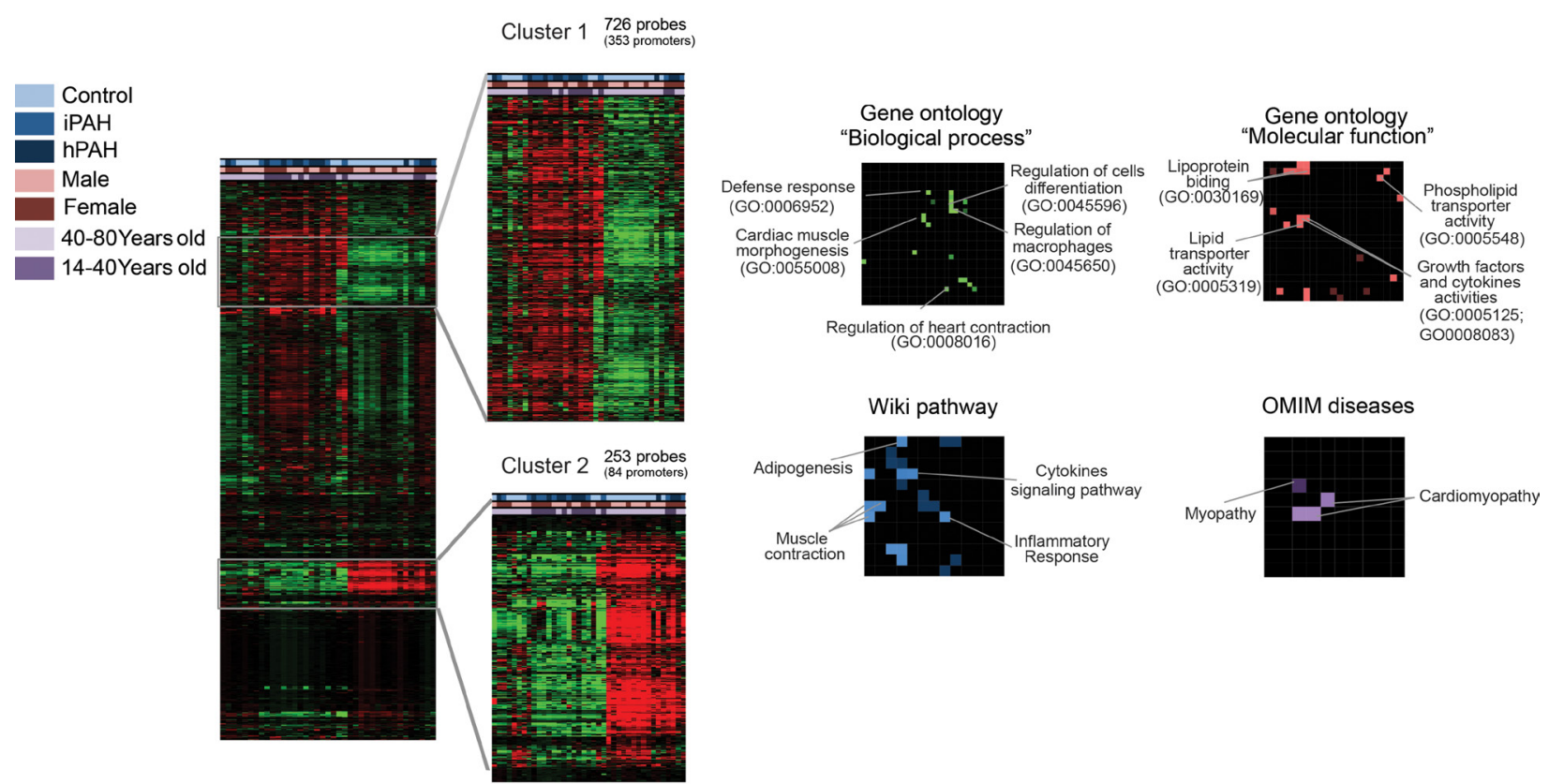

\section{PEC from PAH patients exhibit major epigenetic alterations in the metabolic pathway}

To visualize and understand potential functional interactions of the identified genes, we submitted the same gene lists to Ingenuity pathway analysis (IPA). IPA results in dense networks relating genes to distinct biological functions, as shown in Figure 3A-3C. Figure 3A shows all hyper-methylated (in red) and hypo-methylated (in green) genes potentially correlated with vascular diseases and angiogenesis. DNA hyper-methylation has been observed in promoters already described as deregulated in PAH pathogenesis including the fibroblast growth factor (FGF) family, the receptor of the inflammatory chemokine fractalkine (CX3CR1) and the tumor necrosis factor family (TNFSF4, alias OX40L) [13]. Importantly, we further confirmed the results from unsupervised clustering (Figure 1A) with the presence of a set of interconnected genes related to lipid metabolism such as ADIPOQ, APOA4 and ABCA1 (Figure 3A).

Based on these observations, we conducted a second pathway analysis from the full list of differentially methylated metabolic genes given by IPA (Table 4). Among 48 genes, we found that 28 hyper-methylated and 11 hypo-methylated genes were directly connected to the

Figure 1: Differential DNA methylation pattern in pulmonary endothelial cells from patients with pulmonary arterial hypertension and controls. (A) Heatmap representation of the differential methylated promoters coding for proteins and miRNAs in PAH patients (heritable + idiopathic) compared to controls. Two clusters (cluster 1 and cluster 2) were selected in function of the methylation levels (Over-methylated probes in red and under-methylated probes in green). (B) Enrichment analysis of the differentially methylated promoters as canvases (Network2Canvas software). For each canvas, brighter nodes represent lower $P$-value enriched terms. 


\section{Table 1: Gene Ontology (GO) analysis related to "Biological process" of differentially methylated promoters in PAH patients}

\begin{tabular}{|c|c|c|c|}
\hline Term & $P$-value & Z-score & Genes \\
\hline negative regulation of macrophage differentiation (GO:0045650) & 0.000 & -2.481 & CRP;ABCA1;ADIPOQ;INHBA \\
\hline negative regulation of cell differentiation (GO:0045596) & 0.000 & -2.214 & CRP;ABCA1;ADIPOQ;TWIST2;INHBA;NKX2-5 \\
\hline negative regulation of myeloid cell differentiation (GO:0045638) & 0.001 & -2.446 & CRP;ABCA1;ADIPOQ;INHBA \\
\hline detection of abiotic stimulus (GO:0009582) & 0.001 & -2.109 & RP1;OPN4;GNAT2;TCAP \\
\hline defense response (GO:0006952) & 0.001 & -2.291 & $\begin{array}{c}\text { CX3CR1;CRP;APCS;NFAM1;STAB2;APOA4;INHBA;FAIM3;TYROBP;C } \\
\text { D48;CD300C;S100A9;MBL2 }\end{array}$ \\
\hline negative regulation of foam cell differentiation (GO:0010745) & 0.001 & -1.782 & CRP;ABCA1;ADIPOQ \\
\hline heart development (GO:0007507) & 0.002 & -2.129 & TBX1;TBX5;TDGF1;MYH7 \\
\hline cardiac muscle tissue morphogenesis (GO:0055008) & 0.003 & -2.008 & TCAP;NKX2-5;MYH7 \\
\hline regulation of cell differentiation (GO:0045595) & 0.003 & -2.247 & CRP;ABCA1;ZAP70;ADIPOQ;TWIST2;INHBA;TBX5;NKX2-5 \\
\hline phototransduction (GO:0007602) & 0.004 & -1.793 & RP1;OPN4;GNAT2 \\
\hline anatomical structure morphogenesis (GO:0009653) & 0.004 & -2.148 & $\begin{array}{l}\text { COL1A1;TBX1;MAB21L1;TCAP;TBX5;NKX2- } \\
\text { 5;FGF1;TDGF1;FLI1;DKK3;MYH7 }\end{array}$ \\
\hline regulation of heart contraction (GO:0008016) & 0.004 & -1.872 & DES;HSPB7;NKX2-5;MYH7 \\
\hline $\begin{array}{l}\text { detection of light stimulus involved in visual perception } \\
\qquad \text { (GO:0050908) }\end{array}$ & 0.004 & -1.727 & RP1;OPN4;GNAT2 \\
\hline detection of visible light (GO:0009584) & 0.005 & -1.721 & RP1;OPN4;GNAT2 \\
\hline regulation of myeloid cell differentiation (GO:0045637) & 0.007 & -1.904 & CRP;ABCA1;ADIPOQ;INHBA \\
\hline phospholipid efflux (GO:0033700) & 0.011 & -0.463 & ABCA1;APOA4 \\
\hline cellular defense response (GO:0006968) & 0.013 & -1.765 & CX3CR1;TYROBP;CD300C;FAIM3 \\
\hline antigen processing and presentation (GO:0019882) & 0.013 & -0.310 & CLEC4M;CTSE \\
\hline muscle contraction (GO:0006936) & 0.017 & -1.863 & CHRNA1;DES;MYOT;GJA5;TCAP \\
\hline protein-lipid complex assembly (GO:0065005) & 0.018 & -0.948 & ABCA1;APOA4 \\
\hline negative regulation of lipid storage (GO:0010888) & 0.018 & -0.890 & CRP;ABCA1 \\
\hline response to external stimulus (GO:0009605) & 0.020 & -2.123 & $\begin{array}{c}\text { CX3CR1;CRP;APCS;RP1;OPN4;GNAT2;NFAM1;TCAP;INHBA;S100A } \\
\text { 9;MBL2 }\end{array}$ \\
\hline phospholipid transport (GO:0015914) & 0.021 & -1.010 & ABCA1;APOA4 \\
\hline acute-phase response (GO:0006953) & 0.021 & -0.916 & APCS;MBL2 \\
\hline reverse cholesterol transport (GO:0043691) & 0.021 & -0.911 & ABCA1;APOA4 \\
\hline multicellular organismal metabolic process (GO:0044236) & 0.021 & -0.871 & COL1A1;APOA4 \\
\hline cell-cell junction assembly (GO:0007043) & 0.023 & -0.792 & GJD3;GJA5 \\
\hline detection of stimulus (GO:0051606) & 0.025 & -1.572 & RP1;OPN4;GNAT2;TCAP \\
\hline cholesterol efflux (GO:0033344) & 0.029 & -1.103 & ABCA1;APOA4 \\
\hline positive regulation of cell differentiation (GO:0045597) & 0.032 & -1.745 & ZAP70;INHBA;TBX5;NKX2-5 \\
\hline regulation of gene-specific transcription (GO:0032583) & 0.032 & -1.660 & GFI1;TNFSF4;TBX5;GATA2 \\
\hline regulation of cholesterol transport (GO:0032374) & 0.036 & -1.208 & ADIPOQ;APOA4 \\
\hline $\begin{array}{l}\text { regulation of specific transcription from RNA polymerase II } \\
\text { promoter (GO:0010551) }\end{array}$ & 0.037 & -1.477 & GFI1;TBX5;GATA2 \\
\hline actin filament-based process (GO:0030029) & 0.039 & -1.642 & BMP10;ARHGDIB;TCAP;KPTN;MYH7 \\
\hline negative regulation of gene-specific transcription (GO:0032582) & 0.042 & -1.063 & GFI1;TNFSF4 \\
\hline leukocyte adhesion (GO:0007159) & 0.042 & -0.950 & CLEC4M;APOA4 \\
\hline regulation of transcription (GO:0045449) & 0.048 & -1.857 & $\begin{array}{l}\text { TBX1;TFAP2A;BMP10;GFI1;NFAM1;NR1I2;ARID5A;INHBA;GDF6;TB } \\
\text { X5;GATA2;ETS2;SOX18;TNFSF4;ID3;ALX1;SLC2A4RG;TEAD3 }\end{array}$ \\
\hline cell-cell junction organization (GO:0045216) & 0.050 & -1.099 & GJD3;GJA5 \\
\hline enzyme linked receptor protein signaling pathway (GO:0007167) & 0.050 & -1.676 & BMP10;NRTN;PTN;GDF6;FGF1;TDGF1 \\
\hline
\end{tabular}

Only GO categories with $P$-value less than $5 \%$ are represented.

same network "cholesterol and lipid transport" (Figure 3B). When we focused on the ten top candidates genes hyper- or hypo-methylated (Figure 3C), TP53 (tumor protein 53) was presented directly or indirectly as a common denominator of all genes. In addition, this network integrates other genes with a proved activity in PAH such as angiotensin 
Table 2: Gene Ontology (GO) analysis related to "molecular activity" of differentially methylated promoters in PAH patients

\begin{tabular}{|c|c|c|c|}
\hline Term & $P$-value & Z-score & Genes \\
\hline $\begin{array}{l}\text { RNA polymerase II regulatory region DNA binding } \\
\text { (GO:0001012) }\end{array}$ & 0.00 & -2.42 & $\begin{array}{l}\text { STAT5A;TFAP2A;NR1I2;TBX5;GATA2;ACTB;FLI1;ETS2;NR2F6;SOX18;EL } \\
\text { F5;HAND2;ALX1;NKX2-5 }\end{array}$ \\
\hline $\begin{array}{l}\text { transcription regulatory region sequence-specific } \\
\text { DNA binding (GO:0000976) }\end{array}$ & 0.00 & -2.42 & $\begin{array}{l}\text { STAT5A;TFAP2A;NR1I2;TBX5;GATA2;ACTB;FLI1;ETS2;NR2F6;SOX18;EL } \\
\text { F5;HAND2;ALX1;NKX2-5 }\end{array}$ \\
\hline cytidine deaminase activity (GO:0004126) & 0.00 & -2.03 & APOBEC1;APOBEC2;AICDA \\
\hline virion binding (GO:0046790) & 0.00 & -2.27 & CRP;APCS;CLEC4M \\
\hline $\begin{array}{l}\text { RNA polymerase II transcription regulatory region } \\
\text { sequence-specific DNA binding transcription } \\
\text { factor activity involved in positive regulation of } \\
\text { transcription (GO:0001228) }\end{array}$ & 0.00 & -2.28 & TFAP2A;SOX18;ELF5;HAND2;NR1I2;ALX1;TBX5;GATA2;NKX2-5;FLI1 \\
\hline deaminase activity (GO:0019239) & 0.00 & -2.61 & APOBEC1;APOBEC2;AMPD2;AICDA \\
\hline $\begin{array}{l}\text { RNA polymerase II distal enhancer sequence- } \\
\text { specific DNA binding (GO:0000980) }\end{array}$ & 0.00 & -2.23 & TFAP2A;GATA2;ACTB;FLI1;NR2F6 \\
\hline $\begin{array}{l}\text { hydrolase activity, acting on carbon-nitrogen } \\
\text { (but not peptide) bonds, in cyclic amidines } \\
\text { (GO:0016814) }\end{array}$ & 0.00 & -2.36 & APOBEC1;APOBEC2;AMPD2;AICDA \\
\hline growth factor activity (GO:0008083) & 0.00 & -2.29 & BMP10;CLEC11A;NRTN;PTN;INHBA;GDF6;FGF1;TDGF1 \\
\hline $\begin{array}{l}\text { enhancer sequence-specific DNA binding } \\
\text { (GO:0001158) }\end{array}$ & 0.00 & -2.22 & TFAP2A;GATA2;ACTB;FLI1;NR2F6 \\
\hline $\begin{array}{l}\text { sequence-specific DNA binding RNA polymerase II } \\
\text { transcription factor activity (GO:0000981) }\end{array}$ & 0.00 & -2.30 & $\begin{array}{l}\text { TFAP2A;GFI1;NR112;TBX5;GATA2;FLI1;ETS2;NR2F6;SOX18;ELF5;HAND } \\
\text { 2;ALX1;NKX2-5 }\end{array}$ \\
\hline enhancer binding (GO:0035326) & 0.01 & -2.20 & TFAP2A;GATA2;ACTB;FLI1;NR2F6 \\
\hline hormone activity (GO:0005179) & 0.01 & -2.22 & BMP10;ADIPOQ;OXT;INHBA;CGA;METRNL \\
\hline $\begin{array}{l}\text { RNA polymerase II core promoter proximal region } \\
\text { sequence-specific DNA binding transcription factor } \\
\text { activity (GO:0000982) }\end{array}$ & 0.01 & -2.21 & TFAP2A;SOX18;GFI1;HAND2;GATA2;NKX2-5;FLI1;ETS2 \\
\hline $\begin{array}{l}\text { calcium activated cation channel activity } \\
\text { (GO:0005227) }\end{array}$ & 0.01 & -2.33 & CATSPER4;TRPM5;KCNK18 \\
\hline cytokine activity (GO:0005125) & 0.01 & -2.25 & BMP10;TNFSF4;CMTM5;ADIPOQ;XCL2;SCGB3A1;INHBA;GDF6 \\
\hline $\begin{array}{l}\text { quaternary ammonium group binding } \\
\text { (GO:0050997) }\end{array}$ & 0.01 & -2.22 & CRP;CHRNA1;APOA4 \\
\hline $\begin{array}{l}\text { receptor serine/threonine kinase binding } \\
\text { (GO:0033612) }\end{array}$ & 0.01 & -1.28 & BMP10;INHBA \\
\hline opsonin binding (GO:0001846) & 0.01 & -1.14 & CRP;APCS \\
\hline cholesterol transporter activity (GO:0017127) & 0.01 & -1.06 & $\mathrm{ABCA} 1 ; \mathrm{APOA} 4$ \\
\hline olfactory receptor activity (GO:0004984) & 0.01 & -2.09 & $\begin{array}{l}\text { OR10J1;OR51B2;OR10J5;OR2F1;OR9A2;OR51B6;OR51B5;OR52B4;OR10G } \\
\text { 7;OR7D4;OR2A5;OR2A2 }\end{array}$ \\
\hline sterol transporter activity (GO:0015248) & 0.01 & -1.20 & $\mathrm{ABCA} 1 ; \mathrm{APOA} 4$ \\
\hline $\begin{array}{l}\text { passive transmembrane transporter activity } \\
\text { (GO:0022803) }\end{array}$ & 0.01 & -2.25 & $\begin{array}{l}\text { CHRNA1;GJD3;ASIC5;TRPV6;CATSPER4;GABRA5;GJA5;PDPN;ORAI1;T } \\
\text { RPM5;KCNK18;KCNK4 }\end{array}$ \\
\hline channel activity (GO:0015267) & 0.01 & -2.23 & $\begin{array}{l}\text { CHRNA1;GJD3;ASIC5;TRPV6;CATSPER4;GABRA5;GJA5;PDPN;ORAI1;T } \\
\text { RPM5;KCNK18;KCNK4 }\end{array}$ \\
\hline protein homodimerization activity (GO:0042803) & 0.02 & -2.13 & $\begin{array}{l}\text { CRP;TBX1;TFAP2A;CADM3;ADIPOQ;FAM109B;APOA4;GDF6;PRLR;TER } \\
\text { T;HAND2;CHMP4C;CTSE;NKX2-5;UGT1A8;S100A10 }\end{array}$ \\
\hline antioxidant activity (GO:0016209) & 0.02 & -1.87 & TP53INP1;APOA4;LTC4S;S100A9 \\
\hline aspartic-type endopeptidase activity (GO:0004190) & 0.02 & -1.85 & PIP;CTSE;ASPRV1 \\
\hline $\begin{array}{l}\text { RNA polymerase II core promoter proximal region } \\
\text { sequence-specific DNA binding transcription } \\
\text { factor activity involved in positive regulation of } \\
\text { transcription (GO:0001077) }\end{array}$ & 0.02 & -1.91 & TFAP2A;SOX18;HAND2;GATA2;NKX2-5;FLI1 \\
\hline ion gated channel activity (GO:0022839) & 0.02 & -1.86 & CATSPER4;TRPM5;KCNK18 \\
\hline aspartic-type peptidase activity (GO:0070001) & 0.02 & -1.76 & PIP;CTSE;ASPRV1 \\
\hline enzyme activator activity (GO:0008047) & 0.02 & -2.15 & $\begin{array}{l}\text { DAOA;PCOLCE2;TBC1D21;NCF4;ARHGDIB;PLXNB2;ARHGEF10L;APOA } \\
\text { 4;PTPLAD1;LTC4S;RASAL3;PRLR }\end{array}$ \\
\hline structural constituent of muscle (GO:0008307) & 0.02 & -1.71 & NEBL;MYOT;TCAP \\
\hline phospholipid transporter activity (GO:0005548) & 0.02 & -1.68 & ABCA1;PITPNM3;PLSCR4 \\
\hline $\begin{array}{l}\text { drug transmembrane transporter activity } \\
\text { (GO:0015238) }\end{array}$ & 0.02 & -1.11 & SLC47A1;ABCB4 \\
\hline substrate-specific channel activity (GO:0022838) & 0.02 & -2.03 & $\begin{array}{l}\text { CHRNA1;GJD3;ASIC5;TRPV6;CATSPER4;GABRA5;PDPN;ORAI1;TRPM5 } \\
\text {;KCNK18;KCNK4 }\end{array}$ \\
\hline scavenger receptor activity (GO:0005044) & 0.03 & -1.55 & TMPRSS5;STAB2;HHIPL1 \\
\hline $\begin{array}{l}\text { RNA polymerase II core promoter proximal region } \\
\text { sequence-specific DNA binding (GO:0000978) }\end{array}$ & 0.03 & -1.80 & TFAP2A;SOX18;NKX2-5;ACTB;FLI1;ETS2 \\
\hline lipid transporter activity (GO:0005319) & 0.03 & -1.68 & ABCA1;PITPNM3;PLSCR4;APOA4 \\
\hline
\end{tabular}

Only GO categories with P-value less than $5 \%$ are represented. 
Table 3: Enrichment analysis based on the wiki pathway and OMIM disease libraries for differentially methylated promoters in $\mathrm{PAH}$ patients

\begin{tabular}{lcll}
\hline Term in each category & $\boldsymbol{P}$-value & Z-score & Genes \\
\hline Wiki pathway & & & \\
Hs_Myometrial_Relaxation_and_Contraction_Pathways_ & 0.002 & -1.848 & $\begin{array}{l}\text { IGFBP1;GPR182;ADCY4;GNG8;O } \\
\text { WP289_21289 }\end{array}$ \\
Hs_Statin_Pathway_PharmGKB_WP430_29996 & 0.025 & -1.430 & ABCA1;APOA4 \\
Hs_Statin_Pathway_PharmGKB_WP430_21586 & 0.025 & -1.219 & ABCA1;APOA4 \\
Hs_Nuclear_receptors_in_lipid_metabolism_and_- & 0.044 & -1.191 & ABCA1;ABCB4 \\
toxicity_WP299_21309 & 0.050 & -1.081 & COL1A1;ZAP70 \\
Hs_Inflammatory_Response_Pathway_WP453_21632 & 0.054 & -1.517 & STAT5A;ADIPOQ;ID3;GATA2 \\
Hs_Adipogenesis_WP236_28133 & 0.063 & -1.540 & STAT5A;ZAP70;NFAM1;ARHGDIB \\
Hs_T_Cell_Receptor_Signaling_Pathway_WP69_20823 & 0.073 & -0.866 & DES;TCAP \\
Hs_Striated_Muscle_Contraction_WP383_21484 & 0.088 & -1.116 & STAT5A;BCL2L11 \\
Hs_IL-7_Signaling_Pathway_WP205_21111 & 0.108 & -1.278 & STAT5A;BCL2L11;GATA2 \\
Hs_IL-3_Signaling_Pathway_WP286_21281 & & & \\
OMIM Disease & 0.000 & -1.973 & DES;TCAP;LDB3;MYH7 \\
cardiomyopathy,_dilated & 0.001 & -1.861 & DES;TCAP;LDB3;MYH7 \\
cardiomyopathy & 0.011 & -1.456 & DES;LDB3;MYH7 \\
myopathy & 0.124 & 0.313 & TERT \\
fibrosis & &
\end{tabular}

Only enriched terms with $P$-value less than 5\% are represented.

A. Unsupervised clustering

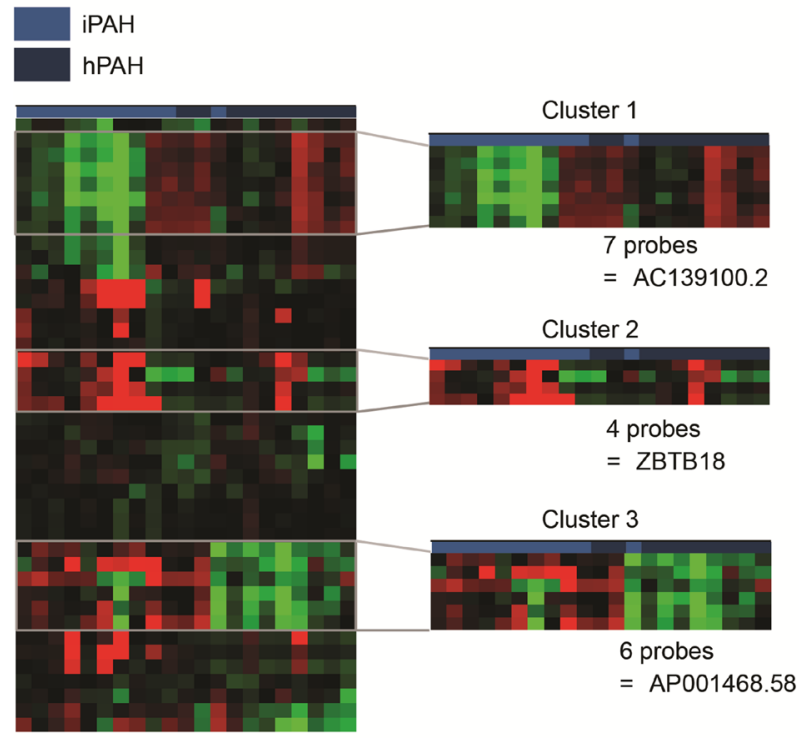

B. Principal component analysis



Hypermethylated genes Hypomethylated genes

Figure 2: idiopathic and heritable PAH patients do not have a distinct endothelial methylation-based signature. (A) Idiopathic PAH patients are represented in light blue and heritable PAH patients in dark blue. On the heatmap, the over- and underexpressed promoters are in red and green, respectively. Only three promoters displayed a differential methylation status, and only one is upstream of a known gene (ZTB18). (B) Principal Component Analysis (PCA) of the methylation profile (promoters) of idiopathic $(n=11)$ and heritable $(n=10) \mathrm{PAH}$ patients. The Pearson correlation coefficient ( $\mathrm{r})$ was calculated comparing the $\mathrm{CpG}$ means across idiopathic and heritable groups. 
Table 4: List of the 48 differentially methylated promoter genes identified by Ingenuity pathway analysis (IPA) to be involved in metabolic processes

\begin{tabular}{|c|c|c|c|c|}
\hline FC & Symbol & Gene Name & Location & Type(s) \\
\hline 2,000 & $\mathrm{ABCA} 1$ & ATP-binding cassette, sub-family A ( $\mathrm{ABC} 1)$, member 1 & Plasma Membrane & transporter \\
\hline 2,000 & АBCB4 & ATP-binding cassette, sub-family B (MDR/TAP), member 4 & Plasma Membrane & transporter \\
\hline 2,000 & ACTB & actin, beta & Cytoplasm & other \\
\hline$-2,000$ & ADAM12 & ADAM metallopeptidase domain 12 & Plasma Membrane & peptidase \\
\hline 2,000 & ADIPOQ & adiponectin, $\mathrm{C} 1 \mathrm{Q}$ and collagen domain containing & Extracellular Space & other \\
\hline 2,000 & APCS & amyloid $\mathrm{P}$ component, serum & Extracellular Space & other \\
\hline 2,000 & APOA4 & apolipoprotein A-IV & Extracellular Space & transporter \\
\hline 2,000 & APOBEC1 & apolipoprotein B mRNA editing enzyme, catalytic polypeptide 1 & Cytoplasm & enzyme \\
\hline 2,000 & ASIC5 & acid sensing (proton gated) ion channel family member 5 & Plasma Membrane & ion channel \\
\hline$-2,000$ & BCL2L11 & BCL2-like 11 (apoptosis facilitator) & Cytoplasm & other \\
\hline 2,000 & $\mathrm{CD} 300 \mathrm{C}$ & CD300c molecule & Plasma Membrane & transmembrane receptor \\
\hline 2,000 & CDH17 & cadherin 17, LI cadherin (liver-intestine) & Plasma Membrane & transporter \\
\hline 2,000 & CLEC4M & C-type lectin domain family 4 , member $\mathrm{M}$ & Plasma Membrane & other \\
\hline 2,000 & COL1A1 & collagen, type I, alpha 1 & Extracellular Space & other \\
\hline 2,000 & CRP & C-reactive protein, pentraxin-related & Extracellular Space & other \\
\hline 2,000 & CX3CR1 & chemokine (C-X3-C motif) receptor 1 & Plasma Membrane & G-protein coupled receptor \\
\hline 2,000 & DKK3 & dickkopf WNT signaling pathway inhibitor 3 & Extracellular Space & cytokine \\
\hline$-2,000$ & ETS2 & v-ets avian erythroblastosis virus E26 oncogene homolog 2 & Nucleus & transcription regulator \\
\hline 2,000 & FAIM3 & Fas apoptotic inhibitory molecule 3 & Plasma Membrane & other \\
\hline 2,000 & FERMT1 & fermitin family member 1 & Plasma Membrane & other \\
\hline 2,000 & FGF1 & fibroblast growth factor 1 (acidic) & Extracellular Space & growth factor \\
\hline 2,000 & GABRA5 & gamma-aminobutyric acid (GABA) A receptor, alpha 5 & Plasma Membrane & ion channel \\
\hline 2,000 & HBG2 & hemoglobin, gamma G & Cytoplasm & other \\
\hline 2,000 & IGFBP1 & insulin-like growth factor binding protein 1 & Extracellular Space & other \\
\hline$-2,000$ & $\mathrm{KLC} 1$ & kinesin light chain 1 & Cytoplasm & other \\
\hline$-2,000$ & let-7 & microRNA let-7a-1 & Cytoplasm & microRNA \\
\hline 2,000 & LPPR4 & lipid phosphate phosphatase-related protein type 4 & Plasma Membrane & phosphatase \\
\hline 2,000 & LTC4S & leukotriene $\mathrm{C} 4$ synthase & Cytoplasm & enzyme \\
\hline 2,000 & MAT1A & methionine adenosyltransferase I, alpha & Cytoplasm & enzyme \\
\hline 2,000 & MGMT & O-6-methylguanine-DNA methyltransferase & Nucleus & enzyme \\
\hline$-2,000$ & $\operatorname{mir}-10$ & microRNA 100 & Other & microRNA \\
\hline 2,000 & mir-133 & microRNA $133 b$ & Cytoplasm & microRNA \\
\hline$-2,000$ & mir-26 & microRNA 26b & Cytoplasm & microRNA \\
\hline 2,000 & MT2A & metallothionein $2 \mathrm{~A}$ & Cytoplasm & other \\
\hline 2,000 & NEBL & nebulette & Plasma Membrane & other \\
\hline 2,000 & NKX2-5 & NK2 homeobox 5 & Nucleus & transcription regulator \\
\hline 2,000 & NR1I2 & nuclear receptor subfamily 1 , group I, member 2 & Nucleus & $\begin{array}{l}\text { ligand-dependent nuclear } \\
\text { receptor }\end{array}$ \\
\hline 2,000 & PRLR & prolactin receptor & Plasma Membrane & transmembrane receptor \\
\hline 2,000 & RNLS & renalase, FAD-dependent amine oxidase & Extracellular Space & enzyme \\
\hline$-2,000$ & S100A10 & S100 calcium binding protein $\mathrm{A} 10$ & Cytoplasm & other \\
\hline 2,000 & S100A9 & S100 calcium binding protein $\mathrm{A} 9$ & Cytoplasm & other \\
\hline 2,000 & SLC1A2 & $\begin{array}{c}\text { solute carrier family } 1 \text { (glial high affinity glutamate transporter), } \\
\text { member } 2\end{array}$ & Plasma Membrane & transporter \\
\hline 2,000 & STAB2 & stabilin 2 & Plasma Membrane & transmembrane receptor \\
\hline$-2,000$ & TNFSF4 & tumor necrosis factor (ligand) superfamily, member 4 & Extracellular Space & cytokine \\
\hline 2,000 & TYROBP & TYRO protein tyrosine kinase binding protein & Plasma Membrane & transmembrane receptor \\
\hline 2,000 & ADAM28 & ADAM Metallopeptidase Domain 28 & Extracellular Space & enzyme \\
\hline$-2,000$ & STAT5A & Signal Transducer And Activator Of Transcription 5A & Nucleus & transcription factor \\
\hline$-2,000$ & MIR1207 & MicroRNA 1207 & Cytoplasm & microRNA \\
\hline
\end{tabular}

$\mathrm{FC}=$ Fold change (2.000 for hyper-methylated genes and -2.000 for hypomethylated genes). 
Table 5: Gene expression meta-analysis using NextBio platform on all ABC transporters genes in PAH

\begin{tabular}{cc}
\hline ABC subtypes & $\begin{array}{c}\text { Fold change in the bioset:" Lung idiopathic PAH versus healthy } \\
\text { control" (Rajkumar R et al., 2010) }\end{array}$ \\
\hline Abca1 & -3.01 \\
Abca8 & -1.85 \\
Abca9 & -1.85 \\
Abca10 & -2.24 \\
Abca11 & -1.44 \\
Abcb6 & -1.87 \\
Abcb10 & -1.85 \\
Acb12 & -1.85 \\
Abcc5 & -2.38 \\
Abcc6 & 1.86 \\
Abcc9 & -1 \\
Abcd3 & -2.5 \\
Abcf2 & -1.47 \\
Abcg1 & 1.97 \\
\hline
\end{tabular}

converting enzyme (ACE), angiotensin (ANG) or PPAR- $\delta$ [14]. Among these top genes, we selected the most differentially methylated promoter regions across the visualization of the targeted loci (Figure 3D and 3E). Altogether, these data suggest that cholesterol metabolism is closely associated with PAH.

\section{ABCA1, a target in the pathogenesis of PAH}

In most cases, methylation of $\mathrm{CpG}$ dinucleotides leads to an altered expression of the gene under regulatory control. By assuming that DNA methylation of the genes identified by IPA was negatively correlated with their gene expression level, we simulated a predictive relationship between each genes included in the network "metabolism" (Figure 3C, Figure 4). Interestingly, TP53 may activate BCL2L11, ETS2, miR-26 and inhibit the expression of $\mathrm{ABCB} 4$ or $\mathrm{ABCA} 1$. To validate this potential regulatory network, we conducted a meta-analysis on the same genes using Nextbio on six previously published studies (biosets) performed on PAH lung from animal or human (Figure 5). Out of 8 genes (Figure 3D and 3E), only 6 genes were already described in lungs of $\mathrm{PAH}$ patients (Figure 5). Among them, only ABCA1, ADIPOQ and APOA4 were correlated with their methylation status. Indeed, they were found under-expressed (in green) in one (for ADIPOQ) or two biosets (for ABCA1, ADIPOQ) with a score comprised between 10 and 88 (Figure 5). Although the role of ADIPOQ was already identified in PAH [15], the implication of ABCA1 remains unexplored. The ABCA1 gene is a member of the superfamily of ATP Binding cassette $(\mathrm{ABC})$ transporters involved in the regulation of cholesterol and phospholipid homeostasis.
To date, $46 \mathrm{ABC}$ transporters have been identified as important mediators in human diseases. Interestingly, when we conduct a second meta-analysis on the 46 genes coding for $\mathrm{ABC}$ transporters, we showed that 14 of them were under-expressed particularly in lung from idiopathic PAH patients compared to controls (Table 5). Interestingly, $\mathrm{ABCA} 1$ was the candidate gene with the highest fold change, highlighting the importance of its functional activity ( $\mathrm{FC}=-3.01$, Figure 6 ). Indeed, an altered regulation of $\mathrm{ABCA} 1$ can lead to an increase of inflammation and apoptosis, two majors contributing factors to PAH (Figure 6) but also can impair the cholesterol and lipid transport and leukocytes migration. Since transplanted PAH patients are younger than lung cancer-affected controls, it was impossible to match both groups for age. It is important to note that ABCA1 methylation status was not correlated to the age (Figure 7). Additionally, we determined by immunohistochemistry that there is a specific in situ loss of ABCA1 expression in pulmonary artery endothelial cells from PAH patients (Figure 8A-8D). We confirmed by qPCR the downregulation of ABCA1 at the mRNA level in PAH lungs as compared to age- and sex-matched unused transplant donors obtained from University Hospital Giessen (Giessen, Germany) (Figure 8E). ABCA1 down regulation was specific for group $1-\mathrm{PAH}$, but not for CTEPH and COPD-PH (Figure 8F). Interestingly, we demonstrated that the ABCA1-activating compound T0901317 ameliorated MCT-induced PH with improvement in RV hypertrophy (Figure 9A), and pulmonary hemodynamics (decrease in mean pulmonary artery pressure (mPAP) and total pulmonary vascular resistance (TPR)) (Figure 9B and 9D), without affecting 
systemic pressures measured in carotid artery (CASP) (Figure 9E). The decrease in TPR in T0901317-treated $\mathrm{PH}$ rats was linked to a decrease in the percentage of the resistive fully muscularized distal microvessels (Figure 9H). Thus, these results suggest a role of ABCA1 in the pathophysiology of PAH.

\section{DISCUSSION}

We have addressed the inherited non mutationassociated causes of PEC proliferation in PAH. Indeed, a majority of PAH patients have no identified genetic triggers and PEC isolated from PAH lungs maintain their in vivo characteristics when placed in culture, suggesting epigenetic abnormalities [16]. Among epigenetic marks, we chose to analyze whole genome DNA methylation by combination of Infinium HumanMethylation450 assays and bioinformatic tools (Figure 10).

Cell culture has allowed substantial contributions to $\mathrm{PAH}$ translational research and biomedical discovery and are being widely used. Indeed, the conservation of an abnormal cellular phenotype outside their natural habitats has been demonstrated for primary cultures at early passages. In severe PAH, cultured PECs exhibit hyperproliferative and apoptosis-resistant phenotypes contributing to the extensive pulmonary vascular remodeling observed in $\mathrm{PAH}$, as well as proinflammatory phenotypes [17]. For these reasons, we chose to use cultured



C



D

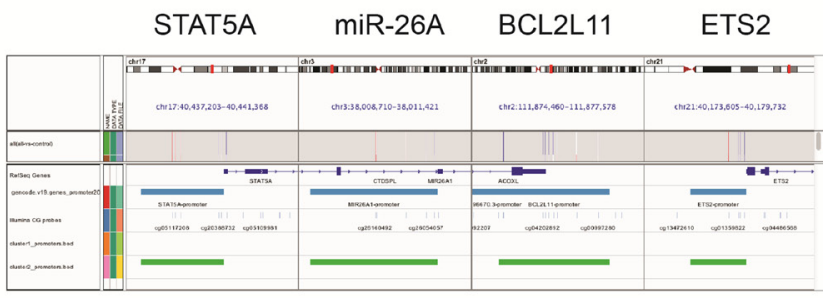

E

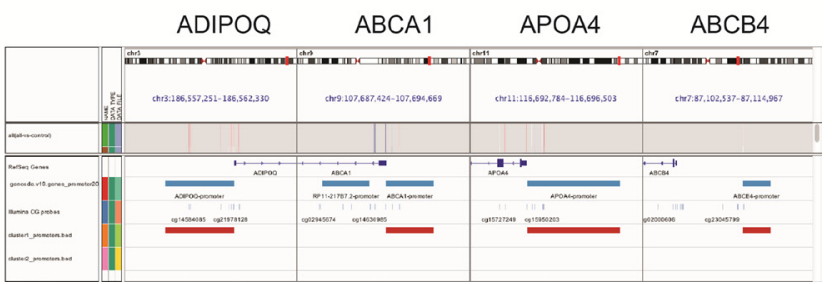

Figure 3: Epigenetic variations in promoters related to the lipid and cholesterol pathway. (A-C) Gene network generated by Ingenuity Pathway Analysis (IPA) on the differentially methylated promoters between PAH patients and controls. Over-methylated genes are represented in red and under-methylated genes in green. (D-E) Visualization of the under-methylated (D) versus hyper-methylated locus (E) in a selection of promoters with Integrative Genomics Viewer (IGV). 
PECs in our study, even if Nestor et al [18] demonstrated that a rapid, global loss of 5-hydroxymethylcytosine ( $5 \mathrm{hmC})$, but not 5-methylcytosine $(5 \mathrm{mC})$, occurs during adaptation of mammalian cells to culture. This epigenetic remodeling was paralleled by extensive gene expression changes in culture, linked to cell adhesion and extracellular matrix organization. Actually, these changes probably reflect adaptation to growth on a two-dimensional plastic surface [18].

The genome-wide DNA methylation profile of PEC from $\mathrm{PAH}$ patients provides three differential signatures composed by hyper- or hypo-methylated promoters when compared to control. We observed that these patterns were not dependent of the age, gender and genetic causes of PAH (Figure 1A). Indeed, we showed that only three promoters (ZBTB18, AP001468.58, AC139100.2) were differentially methylated between idiopathic and heritable PAH (Figure 2A). ZBTB18 (also known as TAZ1 or RP58) has never been implicated in PAH, but its role in mitochondria [19] and as a transcriptional repressor regulating ID family genes, important downstream targets of BMP/ TGFb signalling [20] may be relevant in the disease pathophysiology [21-23]. Our analysis highlighted a similar methylation profile between heritable and idiopathic PAH (Figure 2B) which is concordant with a previous study showing an identical gene expression pattern in PASMCs from idiopathic and heritable PAH [24].
To characterize sets of differentially methylated promoters, we performed a gene ontology and network analysis. The hyper and hypo-methylated promoters in PAH compared to controls were mainly associated with angiogenesis and vascular diseases (Figures 1B, 3A, Tables 2-4). We observed a dysfunction in the promoters DES, ETS2, TERT, MYH7, TBX1/5 playing a major role in heart contraction and morphogenesis [25-28] but also in promoters involved in inflammation and remodeling (growth factor and cytokines activities) such as TNFSF4, COL1A1 and FGF1 [29, 30]. These results are in agreement with the central implication of inflammatory mechanisms in PAH [4, 31]. Additionally, our DNA methylation pattern highlighted a network of dysregulated promoters involved in adipogenesis particularly lipid and cholesterol transport (Figure 3B-3E). Among them, we identified the 8 most differentially methylated promoters including ETS2, STAT5A, miR26A, BCL2L11, ADIPOQ, ABCA1, APOA4 and ABCB4. By using IGV, public mRNA-expression data from Nextbio, and IPA, we concluded that ABCA1 was a major hyper-methylated promoter or downregulated gene discriminating $\mathrm{PAH}$ and control (Figures 5-6, Table 5).

ABCA1 belongs to the super-family ATP Binding cassette $(\mathrm{ABC})$ transporters. $\mathrm{ABC}$ transporters are important for pulmonary homeostasis, with at least three cases of persistent $\mathrm{PH}$ of the newborn due to loss-offunction mutations in $A B C A 3$ [32-34]. To date, no study

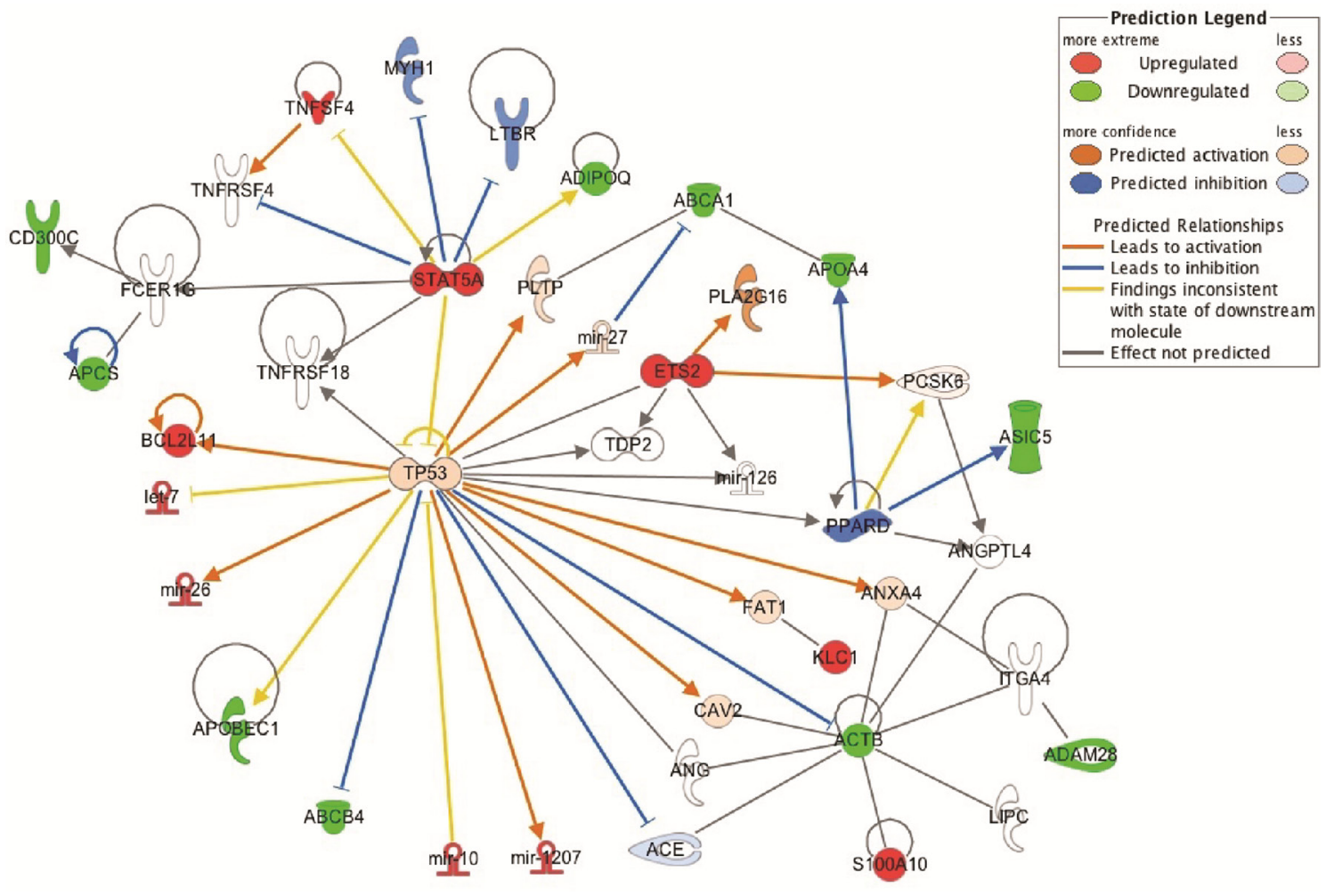

Figure 4: Prediction analysis by IPA on the expression of genes related to the lipid pathway. In red are represented the overexpressed genes ( $=$ hypomethylated promoters) and in green the under-expressed genes ( $=$ hypermethylated promoters). 




Biosets

1 Lungs of Schistosoma-induced pulmonary hypertensive mice_vs_healthy controls

2 Lung from idiopathic pulmonary arterial hypertension patients_vs_normal

3 Lung drom mice with hypoxia-induced pulmonary hypertension at day 3_vs_normoxia

4 Lung from pulmonary hypertension secondary to idiopathic pulmonary fibrosis patients_vs_PAH

5 Lung from rat with pulmonary hypertension from congestive heart failure_vs_control healthy lung

6 Lung from pulmonary hypertension secondary to idiopathic pulmonary fibrosis patients_vs_normal

Figure 5: Validation of the DNA methylation profile using public gene expression data sets obtained in lung tissues from experimental and human pulmonary hypertension. Based on the 10 top genes displaying a significantly different methylation profile described in Figure 3E, a meta-analysis was performed using the NextBio platform. A pair-wise correlation score was computed between 6 biosets (or studies) related to PAH. According to a disease or tissue, this score determines the highly relevant genes through the normalized rank of the gene in the bioset, the number of biosets containing the gene and the number of studies. In red are represented the over-expressed genes (positive fold-change) and in green the under-expressed genes (negative fold-change).

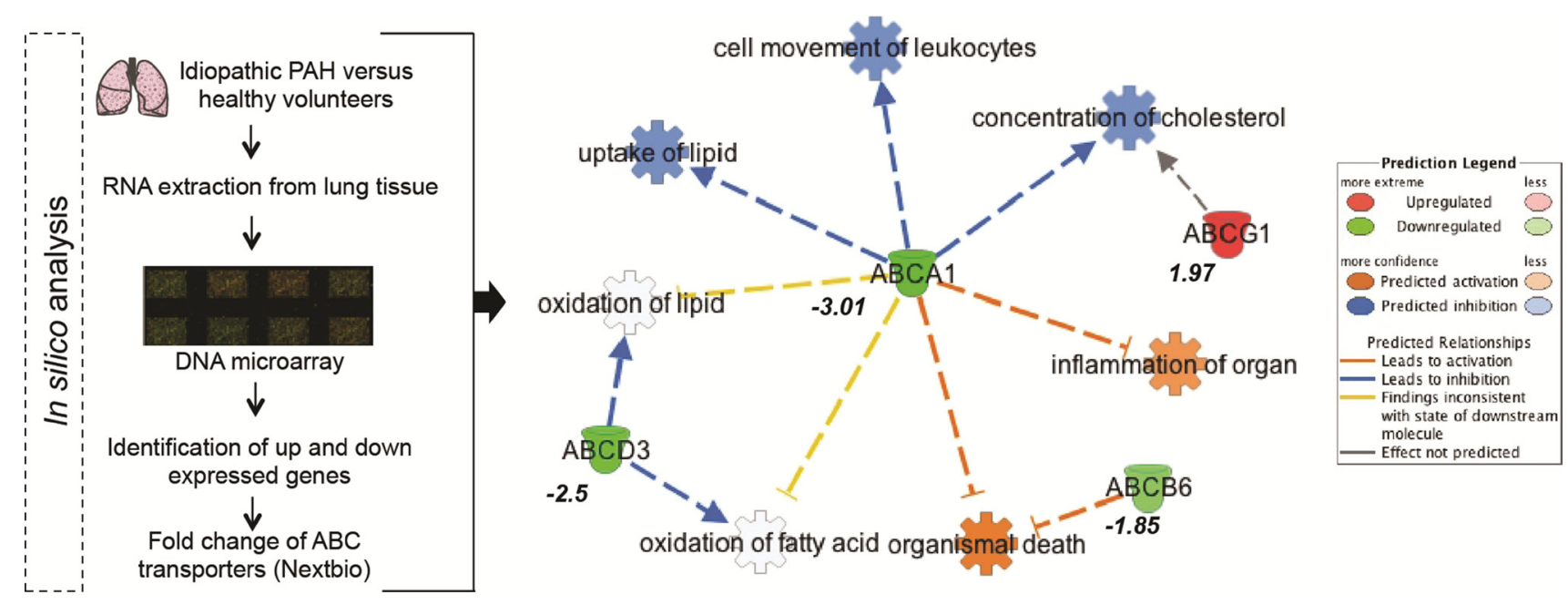

Figure 6: In silico gene expression analysis reveals a major functional role for ABCA1. Given a list of 14 genes coding for the $\mathrm{ABC}$ transporters, Nextbio provided the Fold-change for each gene related to 1 bioset [86]. Thanks to Ingenuity Pathway Analysis (IPA), a network was constructed to measure the potential impact (or prediction) of each $\mathrm{ABC}$ transporter on «diseases or function annotations». In red are represented the over-expressed genes and in green the under-expressed genes. 
has reported a relationship between $\mathrm{ABCA} 1$ promoters and the pathogenesis of $\mathrm{PAH}$. This protein catalyses the transfer of lipids from various tissues and cells to apolipoprotein A1 containing lipoproteins [35]. This reaction is the ratelimiting step in the biogenesis of high-density lipoprotein (HDL) particles and reverses cholesterol transport [35]. HDL levels are a strong, independent inverse predictor of cardiovascular diseases. The protective effects of HDL cholesterol are most likely multifactorial, including reverse cholesterol transport to the liver [36], antioxidant properties [37], anti-inflammatory properties [38], protection of the endothelium [39], anticoagulant effects [40], activation of the endothelial nitric oxide synthase [41], and enhancement of the half-life of prostacyclin [42]. Interestingly, Guay et al. have recently shown that a higher DNA methylation level in the $A B C A 1$ gene promoter locus was associated with lower HDL-C levels and a previous history of coronary artery disease in familial hypercholesterolemia [43]. The authors confirmed in a second independent study that DNA methylation levels at the $A B C A 1$ gene promoter locus are associated with aging and coronary artery disease in men [44]. Other epigenetic studies showed that aging and prenatal famine exposure are associated with DNA hyper-methylation at the $A B C A 1$ gene promoter locus $[45,46]$. Overall, these results suggest that both in utero and postnatal environments might modulate the $A B C A 1$ epigenetic profile and trigger a long-term susceptibility to cardiovascular diseases
[47-49] including PAH [50-52]. This hypothesis has to be tested in the future. Moreover, the higher methylation identified in the $A B C A 1$ gene promoter may be responsible for the lower circulating HDL content found in PAH. Zamanian et al. [53] showed that female patients with PAH were more likely to be insulin resistant defined by a TG/HDL-C ratio greater than 3.0. These patients had significant lower circulating HDL-C level, independently of their BMI that was not different from controls. It has also been reported a significant decrease in circulating levels of HDL cholesterol in PAH patients, which were associated with worse clinical outcomes [54]. Strikingly, patients with low HDL-C had higher levels of IL-17A, an inflammatory characteristic that we recently identified in PAH [55]. Cracowski et al. [56] were not able to confirm the prognostic value of HDL cholesterol in a multicentre prospective cohort study of patients with incident $\mathrm{PAH}$. However, a recent study performed on a larger cohort demonstrated that HDL was an independent predictor of survival [57]. This is in accordance with a recent study concluding that serum HDL cholesterol levels is a prognostic indicator in patients with idiopathic PAH [58].

Our bioinformatic analysis described a determinant role of the growth-suppressive and proapoptotic transcription factor TP53 in the regulation of the metabolic genes including ABCA1 (Figures 3 and 4). Using IPA, we showed that a predictive activation of TP53 downregulates ABCA1. Such an activation is in

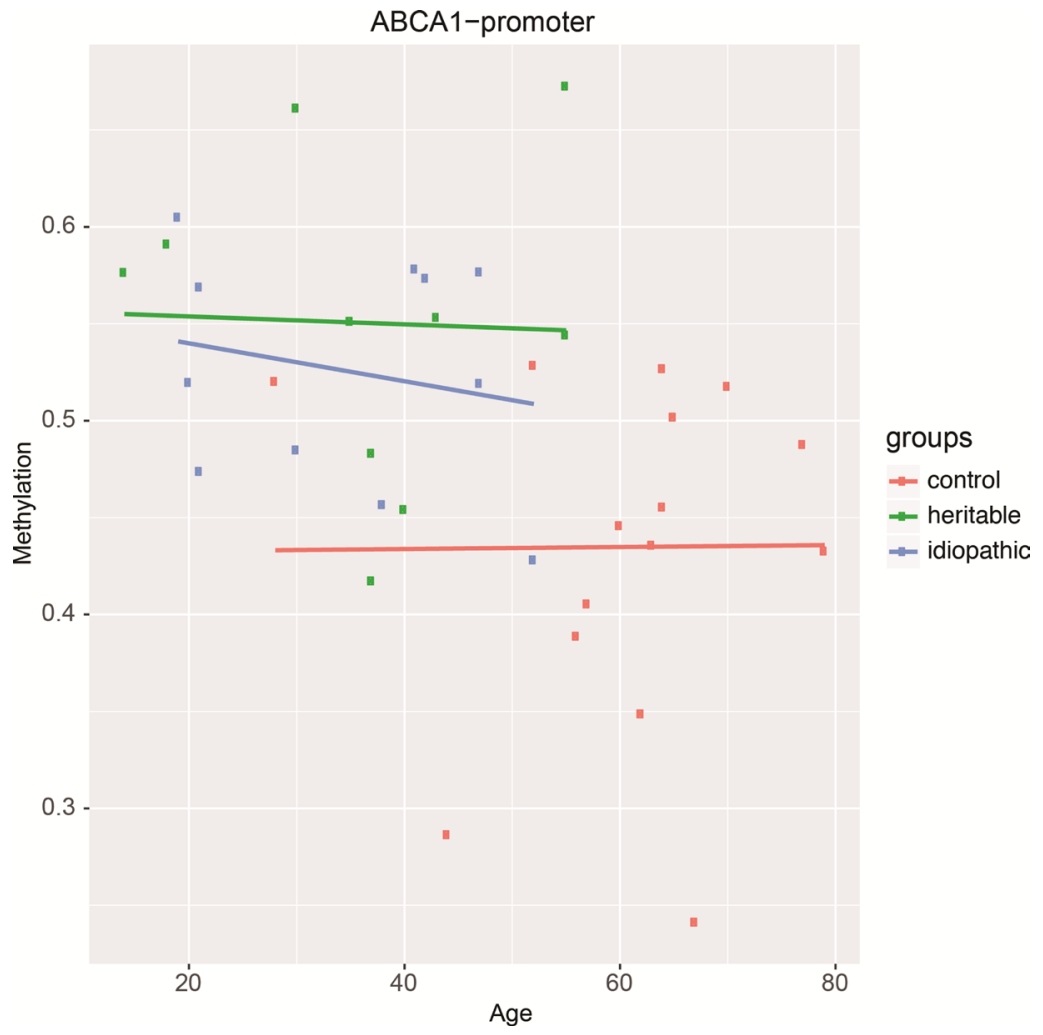

Figure 7: The methylation status of the ABCA1 promoter is not related to age in PEC from controls, and idiopathic and heritable PAH. 
contradiction with results obtained in experimental $\mathrm{PH}$ showing that at the whole-organism scale, inactivation of TP53 is sufficient to induce $\mathrm{PH}$ in rats [59] and that its activation prevents and reverses $\mathrm{PH}$ in mice exposed to chronic hypoxia or SU5416/hypoxia [60]. Inactivation of TP53 is expected to promote the aberrant cancer-like PASMC proliferation, responsible for medial hypertrophy and distal neomuscularization leading to pulmonary vasculature occlusion and increased pulmonary vascular resistance in these models of $\mathrm{PH}$. However, at the specific endothelial level, activation of TP53 inhibits angiogenesis [61]. Hence endothelial specific TP53 activation may be responsible for the pulmonary vascular pruning, loss of cardiac and peripheral muscle microcirculation that increases pulmonary vascular resistance and contribute to exercise intolerance in human PAH $[62,63]$. Herein, our methylation profile suggests that TP53 metabolic targets could play a role in impaired angiogenesis that is a neglected aspect of PAH pathobiology. However, even if TP53 is regulated mainly through protein turnover, its activity is also regulated through critical contextspecific or fine-tuning events, mediated primarily through post-translational mechanisms, particularly multi-site phosphorylation and acetylation [64]. The regulation of TP53 in PAH endothelial cells remains a complex mechanism which deserves further consideration.

In summary, our methylation analysis provides the first map of DNA methylation-base epigenetic predispositions of PEC dysfunction in PAH. This approach allowed us to describe that PEC dysfunction in PAH is related to epigenetic modifications in genes involved in the cholesterol and lipid transport.
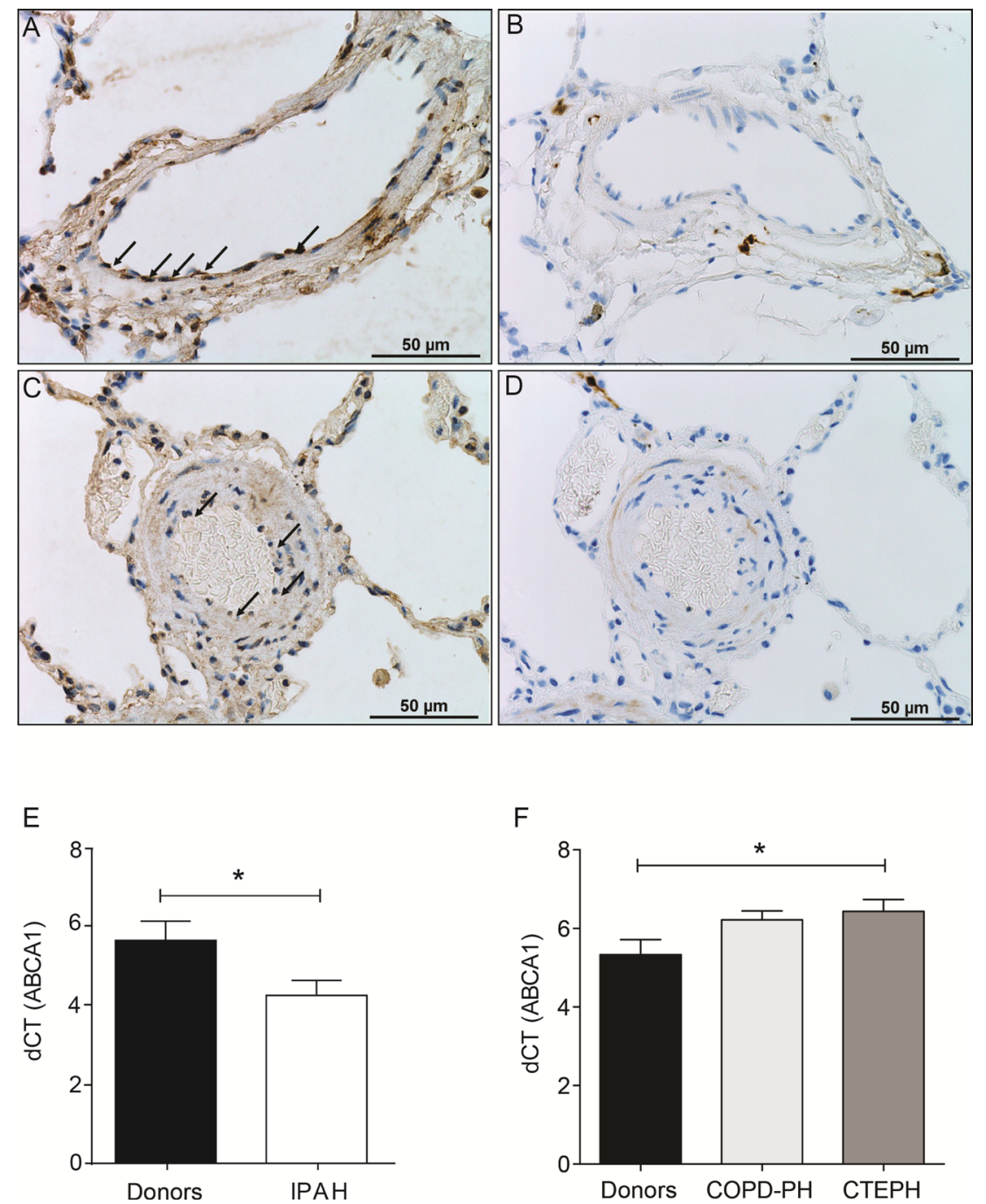

Figure 8: Loss of protein expression of ABCA1 in PAH PEC and decreased mRNA expression of ABCA1 in lungs from PAH patients. Immunohistochemistry with mouse anti-ABCA1 antibody (A and C) or control isotype (IgG2b) mouse antibody (B and $\mathbf{D})$ in healthy (A and B) or PAH (C and D) lungs. Real-time polymerase chain reaction quantification of gene expression showed a significant decrease of ABCA1 mRNA normalized to b-actin mRNA in total lungs from patients with IPAH $(n=7)$ compared with control subjects (donors) $(n=7)(\mathbf{E})$. There was no ABCA1 down regulation in CTEPH $(n=8)$ and COPD-PH $(n=9)$ compared with control subjects (donors) $(n=7)(\mathbf{F})$. Data are represented as mean $+/$ SEM, ${ }^{*} P<0.05$. 

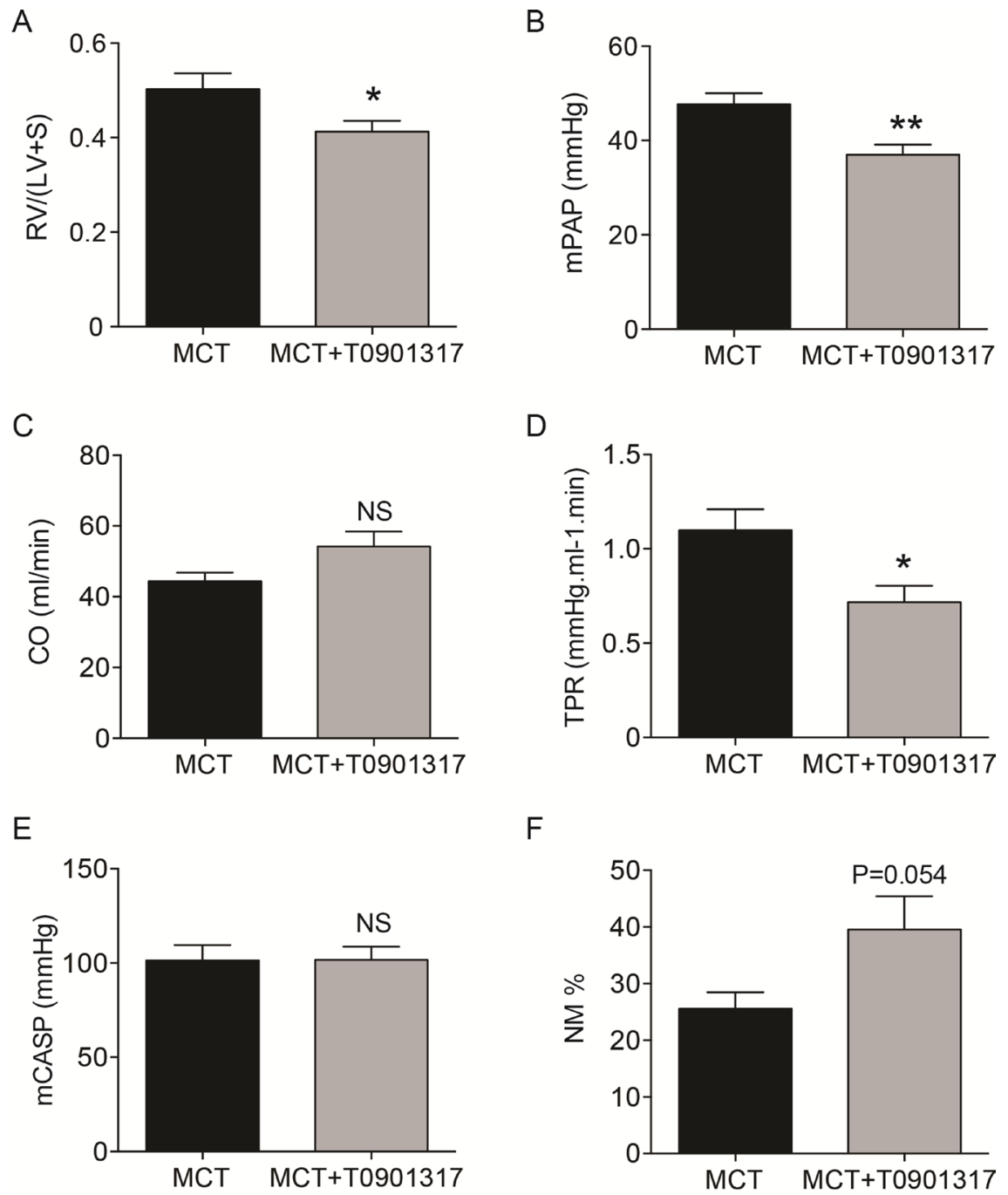

F

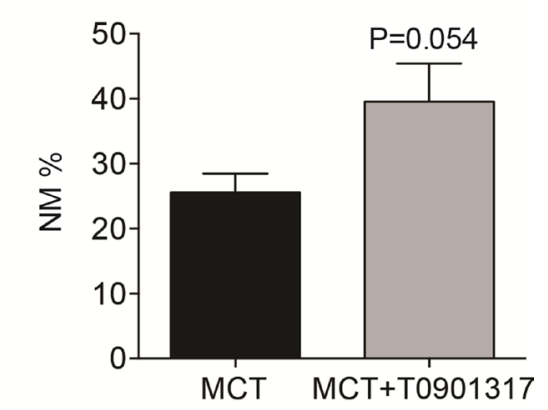

G

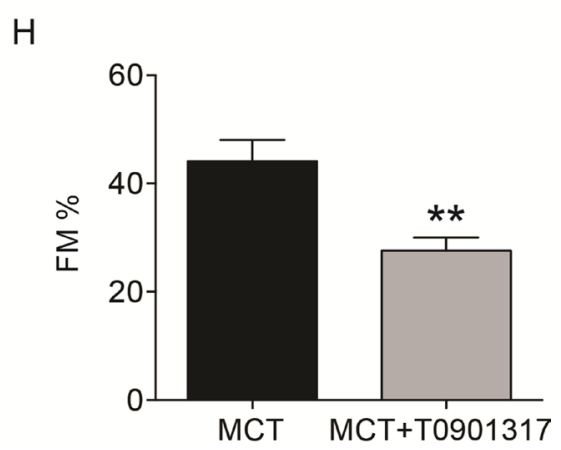

Figure 9: In vivo effects of the ABCA1-activating compound T0901317 on hemodynamics, right heart hypertrophy and pulmonary vascular remodeling in monocrotaline-induced pulmonary hypertension in rats. Two groups were compared: 1) a monocrotaline (MCT) and solvent (ethanol)-exposed group (MCT); 2) a MCT-exposed and $10 \mathrm{mg} / \mathrm{kg} /$ day (days 14-21) T0901317-treated group (MCT+T0901317). In vivo effects of T0901317 on (A) Fulton's index of right ventricular hypertrophy, calculated as the ratio of the right ventricular weight-to-left ventricular plus septal weight $(\mathrm{RV} / \mathrm{LV}+\mathrm{S}),(\mathbf{B})$ mean pulmonary artery pressure (mPAP) $(\mathrm{mm} \mathrm{Hg}),(\mathbf{C})$ cardiac output $(\mathrm{CO})(\mathrm{ml} / \mathrm{min}),(\mathbf{D})$ total pulmonary vascular resistance (TPR) (mmHg.ml $\left.{ }^{-1} \cdot \mathrm{min}\right)$ and $(\mathbf{E})$ mean carotid artery systemic pressure (mCASP) ( $\mathrm{mmHg}$ ). The analysis of the neomuscularization of normally non-muscularized small distal pulmonary artery $(\mathrm{PA})(\leq 50 \mu \mathrm{m})$ is a common and robust way to quantify the degree of remodeling of the rat pulmonary vasculature. (F) Percentage of non-muscularized (NM) PA. (G) Percentage of partially muscularized (PM) PA. (H) Percentage of fully muscularized (FM) PA. MCT and MCT + T0901317: $5 \leq \mathrm{n} \leq 7$. Numbers vary due to death of the animals and/or failure to record the pressures. $* P<0.05, * * P<0.01$. 
Our study has several strengths. The use of whole tissue results in the average of the various methylation profiles coming from diverse cell types. Additionally, lung sections may contain vessels of different sizes and may have differing cell composition, which makes it difficult to interpret the results with regard to relevant biological processes [65]. To overcome tissue heterogeneity and to specifically address the epigenetic origin of PEC dysfunction, we analyzed DNA from isolated primary PEC from controls and PAH patients. Moreover, mRNAbased expression profile may be lost during cell passage and directly influenced by culture conditions. We thus provided stable and long-lasting DNA-based methylation profile to identify non mutation-based epigenetic predispositions to PAH. Only two studies have analyzed the expression profile specifically in PEC from human and experimental $\mathrm{PH}[66,67]$ and they only highlighted two well-known signaling pathways altered in PAH (BMPR2 downstream pathways and Notch signaling). However, both studies used very limited number of samples (three controls and $\mathrm{PH}$ cases). We performed a much more powerful study analyzing DNA from 11 idiopathic PAH, 10 heritable $\mathrm{PAH}$, and from 18 controls. Importantly, we identified DNA methylated genes and gene networks that are commonly regulated between idiopathic and hereditary PAH. This can provide novel therapeutic options that can be useful for various subgroups of PAH. Our study has limitations as well. We focused on the methylation profile of gene promoters. Indeed, the methylation status of promoter associated $\mathrm{CpG}$ islands can directly affect gene transcription. However, the role of the $\mathrm{CpG}$ methylation outside the immediate promoter region remains somewhat unclear. Methylation of $\mathrm{CpG}$ island shores outside the promoter could also control transcription of downstream genes [68] or lead to histone modifications [69]. Methylation changes that occur in intragenic regions could impact RNA splicing [70]. In addition, methylation changes may affect the expression of non-coding RNAs [71] and thus indirectly affect global changes in gene expression. Another limitation of our methylation analysis is that our control tissues were from aged patients with lung cancer. The concept of field cancerization (accumulation of genetic and/or epigenetic alterations in normal-appearing tissues surrounding the cancer) has been indicated for liver, colon, Barrett's esophageal, lung, breast, and renal cancers, and can include changes in DNA methylation $[72,73]$. Therefore, some differences between control and PAH could be related to cancer in the controls and not to PAH. However, the lung specimens from our controls were collected at distance from tumor foci. In any case to exclude the possibility of ABCA1 DNA methylation and subsequent gene regulation in the control tissues, we performed qPCR from the donor lung tissue (taken from the lung that was not transplanted). Indeed, we could confirm down regulation of ABCA1 expression in PAH tissues and endothelial cells compared to age- and

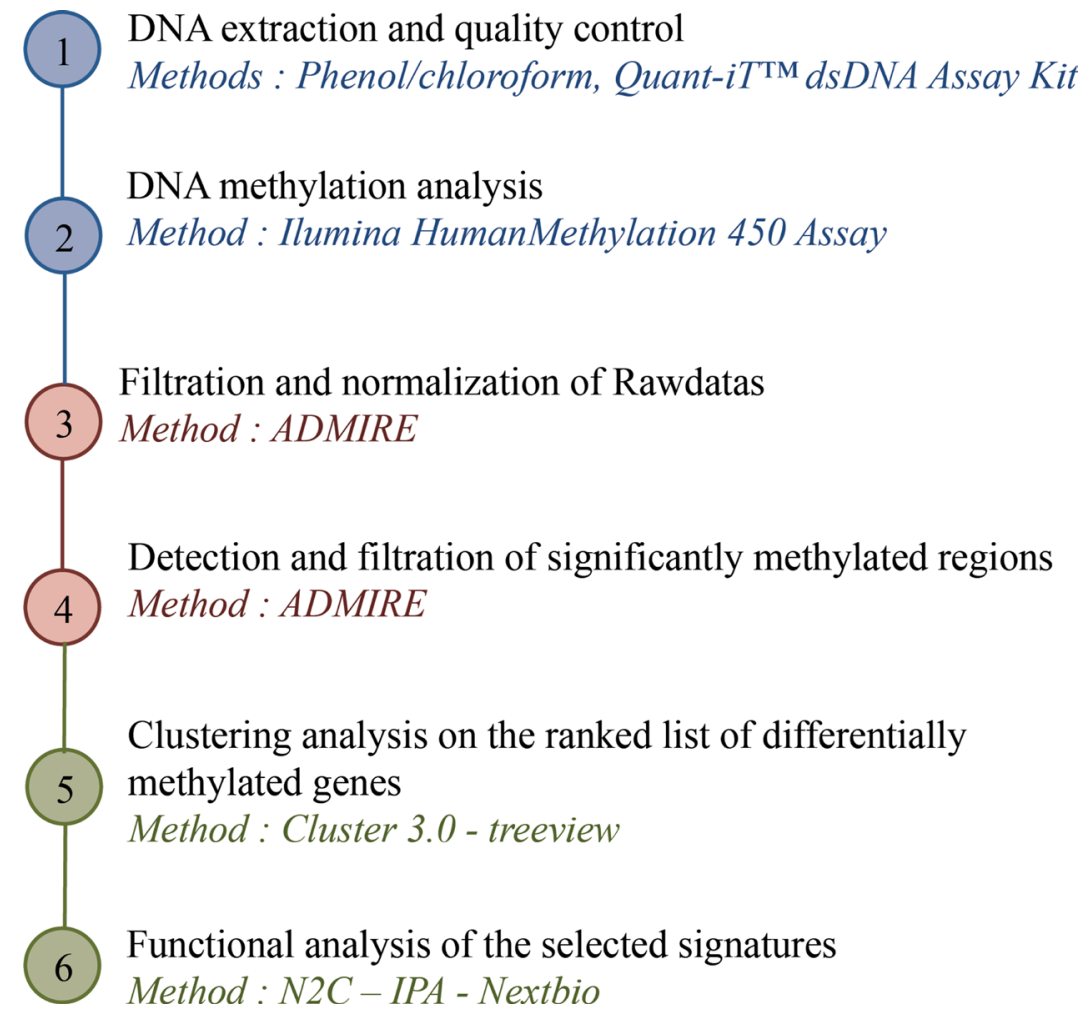

Figure 10: Strategy of DNA methylation analysis: from DNA to targeted promoters. 
sex- matched unused transplant donors (Figure 8A-8E), suggesting ABCA1 regulation is associated with $\mathrm{PAH}$. Interestingly, there was no ABCA1 down regulation in CTEPH and COPD-PH lungs (Figure 8F), suggesting that ABCA1 is specifically downregulated in group $1 \mathrm{PH}$ but not in at least group 3 and $4 \mathrm{PH}$. We didn't have tissues available from other $\mathrm{PH}$ groups. This qPCR-based confirmation of ABCA1 downregulation in PAH was carried over on lung tissues. It is therefore possible that ABCA1 downregulation affects other cell type of the pulmonary vasculature and parenchyma. The potential downregulation of ABCA1 in these other pulmonary cells like fibroblasts may also play a role in the PAH pathobiology [74]. Moreover, we confirmed the relevance of $\mathrm{ABCA} 1$ downregulation in $\mathrm{PAH}$ in an in vivo experiment. We designed an ABCA1 activation-based curative strategy for experimental $\mathrm{PH}$ induced in rat by monocrotaline (MCT) exposure. Since liver $\mathrm{X}$ receptor (LXR) regulates ABCA1 expression in endothelial cells [75], we treated MCT-exposed rats from day 14 to day 21 (symptomatic phase of the model) [76] with the LXR-activating ligand T0901317 at $10 \mathrm{mg} / \mathrm{kg} /$ day [77]. Importantly, the use of a ABCA1 activator (T0901317) improved MCT-induced $\mathrm{PH}$ at the hemodynamic and morphological levels (heart and pulmonary vasculature). This experiment validated ABCA1 downregulation as a pathomechanism of PAH and made the proof-of-concept that its targeting may offer novel therapeutic options.

In conclusion, unlike genetic mutations, epigenetic changes, and DNA methylation in particular, are pharmacologically reversible, which makes them an attractive target in future PAH drug development. Of note, two clinically used compounds with DNA demethylating activities, azacitidine and decitabine, have been recently approved for haematological malignancies [78]. Our present study has identified new pathological pathways potentially involved in PAH and proposes a new concept for $\mathrm{PAH}$ predisposition based on DNA methylation patterns.

\section{MATERIALS AND METHODS}

\section{Patient groups}

PAH patients studied in the methylation analysis were part of the French Network on Pulmonary Hypertension, a program approved by our institutional Ethics Committee, and had given written informed consent. Lung specimens were obtained during lung transplantation. Control patients had undergone lobectomy at our institution (Marie Lannelongue Hospital), either for adenocarcinoma or for squamous cell carcinoma and had given informed consent. Age was $34.4 \pm 12.5$ years and $36.4 \pm 13.5$ years in the patients with idiopathic PAH (IPAH) and heritable PAH (HPAH) due to BMPR2 mutation (except for one case of familial PAH with no detectable mutation) and $60 \pm 12.2$ years in the control subjects. In the groups with IPAH and HPAH, the mean pulmonary artery pressure was, respectively, $61.1 \pm 14.4$ $\mathrm{mmHg}$ and $57.9 \pm 9.9 \mathrm{mmHg}$; and mean pulmonary vascular resistance was $14.9 \pm 6.9$ and $9.4 \pm 2$ Wood units. Transthoracic echocardiography was performed preoperatively in the control subjects to rule out pulmonary hypertension.

mRNA and protein expression of selected targets were confirmed in totally unrelated pulmonary samples from University Hospital Giessen (Giessen, Germany). To rule out the possibility that some differences between control and PAH could be related to cancer in the controls and not to PAH, we used age- and sex-matched unused transplant donor lungs as controls in this validation analysis (mean age $52.7 \pm 17.2$ years, $n=7$ ).

The study protocol for tissue donation was approved by the ethics committee (Ethik Kommission am Fachbereich Humanmedizin der Justus Liebig Universität Giessen) of the University Hospital Giessen (Giessen, Germany) in accordance with national law and with Good Clinical Practice/International Conference on Harmonisation guidelines. Written informed consent was obtained from each individual patient or the patient's next of kin (AZ 31/93). Mean Age was 43.8 \pm 10.1 years in the patients with idiopathic PAH (IPAH) $(n=7), 55.1 \pm 6.2$ years in the patients with COPD associated PH (COPD$\mathrm{PH})(n=9), 44.7 \pm 5.8$ years in the patients with chronic thromboembolic PH (CTEPH) $(n=8)$, and $52.7 \pm 17.2$ years in the control subjects $(n=7)$.

\section{DNA isolation and DNA methylation data analysis}

PEC from patients with idiopathic PAH $(n=11)$, heritable PAH $(n=10)$ and from controls $(n=18)$ were isolated, then cultured as previously described [76] and were used at passage 3. Genomic DNA was extracted from cultured PEC by using the phenol/chloroform method including an RNase treatment. Extracted DNA were quantified for each sample with the kit Quant-IT (Quant-iT ${ }^{\mathrm{TM}}$ dsDNA Assay Kit, Thermo Fisher) and were controlled for quality by gel electrophoresis. DNA methylation was assessed at over 485,000 CpG sites using the Illumina Infinium ${ }^{\circledR}$ HumanMethylation450 BeadChip. The slides were scanned by iScan+ (Illumina ${ }^{\circledR}$, San Diego, USA). Raw data files were used as input for ADMIRE [79], a method for analyzing DNA methylation in genomic regions. Briefly, data was quality checked and normalized using the functional normalization developed by Aryee et al. [80]. Two one-sided two sample Mann-Whitney $U$-tests were done for each $\mathrm{CpG}$ site (post-filter) to account for non-normality of the data and to enable the combination of obtained $p$-values into genomic regions. $\mathrm{CpG}$ sites were mapped onto all $2 \mathrm{~kb}$ regulatory regions upstream a TSS annotated in GENCODE V19 [81] and comb-p [82] 
was used to obtain a multiple-testing corrected q-value for each regulatory region. A q-value of 0.05 (FDR) was used to filter significant differentially methylated regions. Following this method, three files were generated by comparison of the different groups (control versus all (heritable and idiopathic); control versus idiopathic; and control versus heritable) and containing normalized methylation values from differentially methylated regions. For each pairwise comparison, unsupervised hierarchical clustering was performed with Cluster (v3.0) using Spearman Rank correlation with a median-centered gene dataset. TreeView was used to generate the heatmaps and to select individual clusters containing hypermetylated or hypomethylated promoters.

Pearson correlation coefficients were calculated based on normalised methylation values using the $\mathrm{R}$ function cor from the base package. Briefly, the matrix of methylation values with rows corresponding to $\mathrm{CpG}$ sites and columns corresponding to samples was limited to $\mathrm{CpG}$ sites of interest (all promoters) as well as samples from iPAH or hPAH. Next, the correlation was calculated between the group-wise means of $\mathrm{CpG}$ site methylation values.

The methylation data reported in this paper have beens deposited in NCBIs Gene Expression Omnibus (GEO) (Omnibus, 2014) and are accessible with the access number (GSE84395).

\section{Functional and network analysis}

Enrichment analysis of the protein coding-genes for each cluster was assessed using the tool (N2C) [83]. Given the genes of interest, N2C produces visual patterns on canvases of enriched terms. Each square on the canvas represents a functional term, and terms are organized on the canvas based on their gene-set content similarity. This method allows us to create canvases for the following gene-set libraries: GO ontologies (Biological process and molecular function), Wiki pathway and OMIM diseases. The enrichment results for each canvas were displayed in tables thanks to the Enrichr application (http://www. ncbi.nlm.nih.gov/pubmed/23586463) with only the most significant term $(p$-value $<0.05)$. In addition to $\mathrm{N} 2 \mathrm{C}$, we used Ingenuity Pathway Analysis (IPA) to confirm the functional annotations and to create biological networks. A fold change (FC) was attributed for each gene in function of the methylation or expression levels (positive $\mathrm{FC}=$ hypo-methylated or under-expressed genes (green); Negative FC = hyper-methylated or over-expressed genes (red)). In some cases, we extend the method to predict downstream and upstream effects on biological functions of regulated genes.

\section{Integrative genomic viewer (IGV)}

To visualize the methylation region, we used the IGV tool that enables real-time exploration of large datasets including methylation [84]. All data files submitted to IGV are represented in horizontal rows called track. Figure 3D-3E display various tracks including the Genome reference Hg19 (RefSeq Genes), all human promoters (gene promoters), all existing $\mathrm{CG}$ probes (Illumina CG probes) together with all differentially methylated probes between control and $\mathrm{PAH}$ patients (Control vs all). Moreover, additional files from the heatmap analysis were loaded showing the hypo-methylated (cluster 1, Figure 3D) or hyper-methylated (cluster 2, Figure $3 \mathrm{E})$ promoters in PAH patients compared to controls. By evaluating the methylation level (numbers of modified probes) for each promoter, IGV allowed us to focus on the most important genes.

\section{Meta-Analysis using the nextbio platform}

To investigate the expression of gene of interest in PAH disease, the Nextbio application "disease atlas" was used (www.nextbio.com). Given a set of genes, Nextbio can explore gene functions and known associations with disease across more than 10,000 genomic studies contained in its library. Figure 5 shows the gene score based on statistical significance across the biosets (100 to the most significant inside the biosets). For each gene, Nextbio includes an activity value (or Fold change) represented in green (under-expressed gene) and red (overexpressed gene).

\section{Quantitative real time PCR (qPCR)}

Total mRNA was extracted from frozen human lung tissues with the Trizol. Equal amounts of isolated RNA were subsequently transcribed into cDNA using the High capacity RNA-to-cDNA Kit (Applied Biosystems, Germany) according to the manufacturer's instructions. qPCR was then performed with the Taqman gene expression assay kit for ABCA1 and beta-actin (Applied Biosystems, Germany). Expression was analyzed with the $\Delta \mathrm{Ct}$ method. The $\mathrm{Ct}$ values of the target genes were normalized to that of the housekeeping gene (endogenous control) encoding beta-actin using the equation $\Delta \mathrm{Ct}=\mathrm{Ct}_{\text {reference }}-\mathrm{Ct}_{\text {target }}$ and expressed as $\Delta \mathrm{Ct}$.

\section{Immunohistochemical detection of $\mathrm{ABCA1}$ in paraffin-embedded lung tissues}

The staining was performed with a VENTANA BenchMark ULTRA fully automated staining instrument (Roche, Schweiz). After classical dewaxing and heat antigen retrieval at $\mathrm{pH} 6$ (citrate buffer, Protocol CC2), immunohistochemistry was performed with a mouse antiABCA1 (Thermo Scientific, France; Clone: HJ1, Dilution: 1/400, Incubation time: $32 \mathrm{~min}$ ), detected by a biotinylated goat anti-mouse and streptavidin peroxidase (ThermoScientific, France) and permanent AEC kit (Ref ZUC054200, Zytomed, Germany). An unrelated antibody of the 
same isotype as the primary antibody was used in negative controls. Slides were counterstained with hematein.

\section{In vivo study design, measurements, and tissue sampling}

Experiments were conducted according to the European Union regulations (Directive 86/609 EEC) for animal experiments and complied with our institution's guidelines for animal care and handling. The animal facility is licensed by the French Ministry of Agriculture (agreement No. B92-019-01). The Committee on the Ethics of Animal Experiments CEEA26 CAPSud approved the study. Dr. Perros supervised all animal experiments (agreement delivered by the French Ministry of Agriculture for animal experiment No. A92-392). All efforts were made to minimize animal suffering.

Male Wistar rats (100 g body weight) were maintained in a temperature-controlled room with a 12/12-h light/dark cycle and randomly divided into: 1 ) a monocrotaline (MCT) and solvent (ethanol)-exposed group (MCT, $n=8$ ); 2) a MCT-exposed and $10 \mathrm{mg} / \mathrm{kg} / \mathrm{day}$ (days 14-21) T0901317-treated group (MCT+ T0901317, $n=8)$.

All rats had access to standard rat chow and water ad libitum. For MCT administration, rats received a single subcutaneous injection of $60 \mathrm{mg} / \mathrm{kg}$ MCT (Sigma-Aldrich, Lyon, France), which was dissolved in $1 \mathrm{~N} \mathrm{HCl}$ and neutralized with $1 \mathrm{~N} \mathrm{NaOH}$. At day 21, measurement of the right ventricular systolic pressure (RVSP) (mmHg), mean pulmonary artery pressure (mPAP) ( $\mathrm{mmHg}$ ), mean carotid artery systemic pressure (mCASP) $(\mathrm{mmHg})$, cardiac output $(\mathrm{CO})(\mathrm{ml} / \mathrm{min})$, and total pulmonary vascular resistances (TPR) (mmHg. $\mathrm{ml}^{-1}$. min) were recorded as previously described [85]. After rats were exsanguinated, the right lungs were distended by infusion of optimal cutting temperature compound (Miles, Epernon, France) diluted in phosphate-buffered saline (1:1) into the right principal bronchus, quickfrozen in isopentane on dry ice, and stored at $-80^{\circ} \mathrm{C}$. Left lungs were formalin- distended, fixed, and paraffinembedded. For Fulton's index of right ventricular hypertrophy, the ratio of the right ventricular weightto-left ventricular plus septal weight $(\mathrm{RV} / \mathrm{LV}+\mathrm{S})$ was calculated.

\section{Abbreviations}

ABC transporters: ATP Binding cassette transporters; BMPR2: Bone morphogenetic protein receptor type II; GEO: Gene Expression Omnibus; HDL: high-density lipoprotein; IPA: Ingenuity pathway analysis; PAH: Pulmonary arterial hypertension; PASMC: pulmonary arterial smooth muscle cells; PEC: pulmonary endothelial cells.

\section{Authors' contributions}

Study conception and design: AH, JC, JP, SP, JT, ML, JFD, WS, GS, MH and FP; Acquisition of data: AH, JC, SP, JT, ML, FA, MR and FP; Analysis and interpretation of data: AH, JC, JP, SP, JT, ML, FA, DM, BG, SE, GS, MH and FP; Drafting of manuscript and Critical revision: $\mathrm{AH}$, JC, JP, SP, FA, DM, BG, WS, GS, MH and FP.

\section{ACKNOWLEDGMENTS}

We thank Ms Caroline Communaux from the pathology department of the Marie Lannelongue Hospital, for her help on ABCA1 immunohistochemistry.

\section{CONFLICTS OF INTEREST}

Pr. HUMBERT reports grants and personal fees from Actelion, grants and personal fees from Bayer, grants and personal fees from GSK, personal fees from Novartis, personal fees from Pfizer, outside the submitted work; Pr. Simonneau reports grants and personal fees from Actelion, grants and personal fees from Bayer, grants and personal fees from GSK, personal fees from Pfizer, outside the submitted work; Pr. Seeger has received honoraria for consultant activities from Bayer and Novartis, and lecture fees from Actelion, Bayer, Pfizer; Dr. Girerd reports personal fees from Actelion, personal fees from Bayer, personal fees from GSK, personal fees from Pfizer, outside the submitted work; Dr. MONTANI reports grants and personal fees from Actelion, grants and personal fees from Bayer, personal fees from BMS,personal fees from GSK, personal fees from Novartis, personal fees from Pfizer, outside the submitted work; Other authors have nothing to disclose.

\section{FUNDING}

This work was supported by research grants from INSERM, National Funding Agency for Research (ANR) (Grant ANR-13-JSV1-0011-01), Laboratoire d'Excellence (LabEx) en Recherche sur le Médicament et l'Innovation Thérapeutique (LERMIT), Assistance Publique Hôpitaux de Paris (Département Hospitalo-Universitaire Thorax Innovation), Legs Poix (Chancellerie des Universités de Paris), and Federal Ministry of Education and Research (BMBF) (Grant FKZ- 01KX1314) and by the French patient association HTAPFrance. A.H. is supported by a $\mathrm{PhD}$ grant from Région Ile de France (CORDDIM). F.A. is supported by a post-doctoral grant from Aviesan and by Lefoulon Delalande Institute.

\section{REFERENCES}

1. Galiè N, Humbert M, Vachiery JL, Gibbs S, Lang I, Torbicki A, Simonneau G, Peacock A, Vonk Noordegraaf A, 
Beghetti M, Ghofrani A, Gomez Sanchez MA, Georg H, et al. 2015 ESC/ERS Guidelines for the diagnosis and treatment of pulmonary hypertension. Eur Respir J. 2015; 46:1855-6. doi: 10.1183/13993003.51032-2015.

2. Ranchoux B, Antigny F, Rucker-Martin C, Hautefort A, Péchoux C, Bogaard HJ, Dorfmüller P, Remy S, Lecerf F, Planté S, Chat S, Fadel E, Houssaini A, et al. Endothelial-to-mesenchymal transition in pulmonary hypertension. Circulation. 2015; 131:1006-18. doi: 10.1161/ CIRCULATIONAHA.114.008750.

3. Perros F, Montani D, Dorfmüller P, Durand-Gasselin I, Tcherakian C, Le Pavec J, Mazmanian M, Fadel E, Mussot S, Mercier O, Hervé P, Emilie D, Eddahibi S, et al. Plateletderived growth factor expression and function in idiopathic pulmonary arterial hypertension. Am J Respir Crit Care Med. 2008; 178:81-8. doi: 10.1164/rccm.200707-1037OC.

4. Huertas A, Perros F, Tu L, Cohen-Kaminsky S, Montani D, Dorfmüller P, Guignabert C, Humbert M. Immune dysregulation and endothelial dysfunction in pulmonary arterial hypertension: a complex interplay. Circulation. 2014; 129:1332-40. doi: 10.1161/ CIRCULATIONAHA.113.004555.

5. Herve P, Humbert M, Sitbon O, Parent F, Nunes H, Legal C, Garcia G, Simonneau G. Pathobiology of pulmonary hypertension. The role of platelets and thrombosis. Clin Chest Med. 2001; 22:451-8.

6. Humbert M, Lau EMT, Montani D, Jaïs X, Sitbon O, Simonneau G. Advances in therapeutic interventions for patients with pulmonary arterial hypertension. Circulation. 2014; 130:2189-208. doi: 10.1161/ CIRCULATIONAHA.114.006974.

7. Herman JG, Baylin SB. Gene silencing in cancer in association with promoter hypermethylation. N Engl J Med. 2003; 349:2042-54. doi: 10.1056/NEJMra023075.

8. Sanders YY, Ambalavanan N, Halloran B, Zhang X, Liu H, Crossman DK, Bray M, Zhang K, Thannickal VJ, Hagood JS. Altered DNA methylation profile in idiopathic pulmonary fibrosis. Am J Respir Crit Care Med. 2012; 186:525-35. doi: 10.1164/rccm.201201-0077OC.

9. Wauters E, Janssens W, Vansteenkiste J, Decaluwé H, Heulens N, Thienpont B, Zhao H, Smeets D, Sagaert X, Coolen J, Decramer M, Liston A, De Leyn P, et al. DNA methylation profiling of non-small cell lung cancer reveals a COPD-driven immune-related signature. Thorax. 2015; 70:1113-22. doi: 10.1136/thoraxjnl-2015-207288.

10. Archer SL, Marsboom G, Kim GH, Zhang HJ, Toth PT, Svensson EC, Dyck JR, Gomberg-Maitland M, Thébaud B, Husain AN, Cipriani N, Rehman J. Epigenetic attenuation of mitochondrial superoxide dismutase 2 in pulmonary arterial hypertension: a basis for excessive cell proliferation and a new therapeutic target. Circulation. 2010; 121:2661-71. doi: 10.1161/CIRCULATIONAHA.109.916098.

11. Perros F, Cohen-Kaminsky S, Gambaryan N, Girerd B, Raymond N, Klingelschmitt I, Huertas A, Mercier O, Fadel E, Simonneau G, Humbert M, Dorfmüller P,
Montani D. Cytotoxic cells and granulysin in pulmonary arterial hypertension and pulmonary veno-occlusive disease. Am J Respir Crit Care Med. 2013; 187:189-96. doi: 10.1164/rccm.201208-1364OC.

12. Gamen E, Seeger W, Pullamsetti SS. The emerging role of epigenetics in pulmonary hypertension. The European Respiratory Journal. 2016.

13. Rabieyousefi M, Soroosh P, Satoh K, Date F, Ishii N, Yamashita M, Oka M, McMurtry IF, Shimokawa H, Nose M, Sugamura K, Ono M. Indispensable roles of OX40L-derived signal and epistatic genetic effect in immune-mediated pathogenesis of spontaneous pulmonary hypertension. BMC Immunol. 2011; 12: 67. doi: 10.1186/1471-2172-12-67.

14. Liu G, Li X, Li Y, Tang X, Xu J, Li R, Hao P, Sun Y. PPAR $\delta$ agonist GW501516 inhibits PDGF-stimulated pulmonary arterial smooth muscle cell function related to pathological vascular remodeling. Biomed Res Int. 2013; 2013: 903947. doi: 10.1155/2013/903947.

15. Hansmann G, Wagner RA, Schellong S, Perez VA de J, Urashima T, Wang L, Sheikh AY, Suen RS, Stewart DJ, Rabinovitch M. Pulmonary arterial hypertension is linked to insulin resistance and reversed by peroxisome proliferator-activated receptor-gamma activation. Circulation. 2007; 115:1275-84. doi: 10.1161/ CIRCULATIONAHA.106.663120.

16. Pullamsetti SS, Perros F, Chelladurai P, Yuan J, Stenmark K. Transcription factors, transcriptional coregulators, and epigenetic modulation in the control of pulmonary vascular cell phenotype: therapeutic implications for pulmonary hypertension (2015 Grover Conference series). Pulm Circ. 2016; 6:448-64. doi: 10.1086/688908.

17. Bonnet S, Provencher S, Guignabert C, Perros F, Boucherat O, Schermuly RT, Hassoun PM, Rabinovitch M, Nicolls MR, Humbert M. Translating Research into Improved Patient Care in Pulmonary Arterial Hypertension. Am J Respir Crit Care Med. 2017; 195:583-95. doi: 10.1164/ rccm.201607-1515PP.

18. Nestor CE, Ottaviano R, Reinhardt D, Cruickshanks HA, Mjoseng HK, McPherson RC, Lentini A, Thomson JP, Dunican DS, Pennings S, Anderton SM, Benson M, Meehan RR. Rapid reprogramming of epigenetic and transcriptional profiles in mammalian culture systems. Genome Biol. 2015; 16:11. doi: 10.1186/s13059-014-0576-y.

19. Ma L, Vaz FM, Gu Z, Wanders RJ, Greenberg ML. The human TAZ gene complements mitochondrial dysfunction in the yeast taz1Delta mutant. Implications for Barth syndrome. J Biol Chem. 2004; 279:44394-9. doi: 10.1074/ jbc.M405479200.

20. Yokoyama S, Ito Y, Ueno-Kudoh H, Shimizu H, Uchibe K, Albini S, Mitsuoka K, Miyaki S, Kiso M, Nagai A, Hikata T, Osada T, Fukuda N, et al. A systems approach reveals that the myogenesis genome network is regulated by the transcriptional repressor RP58. Dev Cell. 2009; 17:83648. doi: 10.1016/j.devcel.2009.10.011. 
21. Sommer N, Strielkov I, Pak O, Weissmann N. Oxygen sensing and signal transduction in hypoxic pulmonary vasoconstriction. Eur Respir J. 2016; 47:288-303. doi: 10.1183/13993003.00945-2015.

22. Yang J, Li X, Li Y, Southwood M, Ye L, Long L, Al Lamki RS, Morrell NW. Id proteins are critical downstream effectors of BMP signaling in human pulmonary arterial smooth muscle cells. Am J Physiol Lung Cell Mol Physiol. 2013; 305:L312-321. doi: 10.1152/ajplung.00054.2013.

23. Vengethasamy L, Hautefort A, Tielemans B, Belge C, Perros F, Verleden S, Fadel E, Van Raemdonck D, Delcroix M, Quarck R. BMPRII influences the response of pulmonary microvascular endothelial cells to inflammatory mediators. Pflugers Arch. 2016. doi: 10.1007/s00424-016-1899-1.

24. Yu J, Wilson J, Taylor L, Polgar P. DNA microarray and signal transduction analysis in pulmonary artery smooth muscle cells from heritable and idiopathic pulmonary arterial hypertension subjects. J Cell Biochem. 2015; 116:386-97. doi: 10.1002/jcb.24987.

25. Ying Z, Xie X, Bai Y, Chen M, Wang X, Zhang X, Morishita M, Sun Q, Rajagopalan S. Exposure to concentrated ambient particulate matter induces reversible increase of heart weight in spontaneously hypertensive rats. Part Fibre Toxicol. 2015; 12:15. doi: 10.1186/s12989-0150092-6.

26. Mouraret N, Houssaïni A, Abid S, Quarck R, Marcos E, Parpaleix A, Gary-Bobo G, Dubois-Randé JL, Derumeaux G, Boczkowski J, Delcroix M, Blasco MA, Lipskaia L, et al. Role for telomerase in pulmonary hypertension. Circulation. 2015; 131:742-55. doi: 10.1161/ CIRCULATIONAHA.114.013258.

27. Pan Y, Wang ZG, Liu XY, Zhao H, Zhou N, Zheng GF, Qiu XB, Li RG, Yuan F, Shi HY, Hou XM, Yang YQ. A Novel TBX1 Loss-of-Function Mutation Associated with Congenital Heart Disease. Pediatr Cardiol. 2015; 36:1400 10. doi: 10.1007/s00246-015-1173-x.

28. Hnia K, Ramspacher C, Vermot J, Laporte J. Desmin in muscle and associated diseases: beyond the structural function. Cell Tissue Res. 2015; 360:591-608. doi: 10.1007/ s00441-014-2016-4.

29. Golob MJ, Wang Z, Prostrollo AJ, Hacker TA, Chesler NC. Limiting collagen turnover via collagenase-resistance attenuates right ventricular dysfunction and fibrosis in pulmonary arterial hypertension. Physiol Rep. 2016; 4. doi: 10.14814/phy2.12815.

30. Sehgal PB, Yang YM, Miller EJ. Hypothesis: neuroendocrine mechanisms (hypothalamus-growth hormone-STAT5 axis) contribute to sex bias in pulmonary hypertension. Mol Med. 2015. doi: 10.2119/ molmed.2015.00122.

31. Cohen Kaminsky S, Hautefort A, Price L, Humbert M, Perros F. Inflammation in pulmonary hypertension: what we know and what we could logically and safely target first. Drug Discov Today. 2014; 19:1251-6. doi: 10.1016/j. drudis.2014.04.007.
32. Kunig AM, Parker TA, Nogee LM, Abman SH, Kinsella JP. ABCA3 deficiency presenting as persistent pulmonary hypertension of the newborn. J Pediatr. 2007; 151:322-4. doi: 10.1016/j.jpeds.2007.05.054.

33. Danhaive O, Peca D, Boldrini R. ABCA3 mutation and pulmonary hypertension: a link with alveolar capillary dysplasia? J Pediatr. 2008; 152:891-2. doi: 10.1016/j. jpeds.2008.01.019.

34. Ota C, Kimura M, Kure S. ABCA3 mutations led to pulmonary fibrosis and emphysema with pulmonary hypertension in an 8-year-old girl. Pediatr Pulmonol. 2016; 51:E21-23. doi: 10.1002/ppul.23379.

35. Joyce C, Freeman L, Brewer HB, Santamarina-Fojo S. Study of ABCA1 function in transgenic mice. Arterioscler Thromb Vasc Biol. 2003; 23:965-71. doi: 10.1161/01. ATV.0000055194.85073.FF.

36. Fielding CJ, Fielding PE. Molecular physiology of reverse cholesterol transport. J Lipid Res. 1995; 36:211-28.

37. Toikka JO, Ahotupa M, Viikari JS, Niinikoski H, Taskinen M, Irjala K, Hartiala JJ, Raitakari OT. Constantly low HDL-cholesterol concentration relates to endothelial dysfunction and increased in vivo LDL-oxidation in healthy young men. Atherosclerosis. 1999; 147:133-8.

38. Ansell BJ, Navab M, Hama S, Kamranpour N, Fonarow G, Hough G, Rahmani S, Mottahedeh R, Dave R, Reddy ST, Fogelman AM. Inflammatory/antiinflammatory properties of high-density lipoprotein distinguish patients from control subjects better than high-density lipoprotein cholesterol levels and are favorably affected by simvastatin treatment. Circulation. 2003; 108:2751-6. doi: 10.1161/01. CIR.0000103624.14436.4B.

39. Zeiher AM, Schächlinger V, Hohnloser SH, Saurbier B, Just H. Coronary atherosclerotic wall thickening and vascular reactivity in humans. Elevated high-density lipoprotein levels ameliorate abnormal vasoconstriction in early atherosclerosis. Circulation. 1994; 89:2525-32.

40. Griffin JH, Kojima K, Banka CL, Curtiss LK, Fernández JA. High-density lipoprotein enhancement of anticoagulant activities of plasma protein $\mathrm{S}$ and activated protein C. J Clin Invest. 1999; 103:219-27. doi: 10.1172/JCI5006.

41. Yuhanna IS, Zhu Y, Cox BE, Hahner LD, Osborne-Lawrence S, Lu P, Marcel YL, Anderson RG, Mendelsohn ME, Hobbs HH, Shaul PW. High-density lipoprotein binding to scavenger receptor-BI activates endothelial nitric oxide synthase. Nat Med. 2001; 7:853-7. doi: 10.1038/89986.

42. Aoyama T, Yui Y, Morishita H, Kawai C. Prostaglandin I2 half-life regulated by high density lipoprotein is decreased in acute myocardial infarction and unstable angina pectoris. Circulation. 1990; 81:1784-91.

43. Guay SP, Brisson D, Munger J, Lamarche B, Gaudet D, Bouchard L. ABCA1 gene promoter DNA methylation is associated with HDL particle profile and coronary artery disease in familial hypercholesterolemia. Epigenetics. 2012; 7:464-72. doi: 10.4161/epi.19633. 
44. Guay SP, Légaré C, Houde AA, Mathieu P, Bossé Y, Bouchard L. Acetylsalicylic acid, aging and coronary artery disease are associated with ABCA1 DNA methylation in men. Clin Epigenetics. 2014; 6:14. doi: 10.1186/18687083-6-14.

45. Tobi EW, Lumey LH, Talens RP, Kremer D, Putter H, Stein AD, Slagboom PE, Heijmans BT. DNA methylation differences after exposure to prenatal famine are common and timing- and sex-specific. Hum Mol Genet. 2009; 18:4046-53. doi: 10.1093/hmg/ddp353.

46. Talens RP, Christensen K, Putter H, Willemsen G, Christiansen L, Kremer D, Suchiman HED, Slagboom PE, Boomsma DI, Heijmans BT. Epigenetic variation during the adult lifespan: cross-sectional and longitudinal data on monozygotic twin pairs. Aging Cell. 2012; 11:694-703. doi: 10.1111/j.1474-9726.2012.00835.x.

47. Houde AA, Guay SP, Desgagné V, Hivert MF, Baillargeon JP, St-Pierre J, Perron P, Gaudet D, Brisson D, Bouchard L. Adaptations of placental and cord blood ABCA1 DNA methylation profile to maternal metabolic status. Epigenetics. 2013; 8:1289-302. doi: 10.4161/epi.26554.

48. Tobi EW, Lumey LH, Talens RP, Kremer D, Putter H, Stein AD, Slagboom PE, Heijmans BT. DNA methylation differences after exposure to prenatal famine are common and timing- and sex-specific. Hum Mol Genet. 2009; 18:4046-53. doi: 10.1093/hmg/ddp353.

49. Talens RP, Christensen K, Putter H, Willemsen G, Christiansen L, Kremer D, Suchiman HE, Slagboom PE, Boomsma DI, Heijmans BT. Epigenetic variation during the adult lifespan: cross-sectional and longitudinal data on monozygotic twin pairs. Aging Cell. 2012; 11:694-703. doi: 10.1111/j.1474-9726.2012.00835.x.

50. Lv Y, Tang LL, Wei JK, Xu XF, Gu W, Fu LC, Zhang LY, Du LZ. Decreased Kv1.5 expression in intrauterine growth retardation rats with exaggerated pulmonary hypertension. Am J Physiol Lung Cell Mol Physiol. 2013; 305: L856-865. doi: 10.1152/ajplung.00179.2013.

51. Xu XF, Lv Y, Gu WZ, Tang LL, Wei JK, Zhang LY, Du LZ. Epigenetics of hypoxic pulmonary arterial hypertension following intrauterine growth retardation rat: epigenetics in PAH following IUGR. Respir Res. 2013; 14: 20. doi: 10.1186/1465-9921-14-20.

52. Zhang L, Tang L, Wei J, Lao L, Gu W, Hu Q, Lv Y, Fu L, Du L. Extrauterine growth restriction on pulmonary vascular endothelial dysfunction in adult male rats: the role of epigenetic mechanisms. J Hypertens. 2014; 32:2188-2198; discussion 2198. doi: 10.1097/HJH.0000000000000309.

53. Zamanian RT, Hansmann G, Snook S, Lilienfeld D, Rappaport KM, Reaven GM, Rabinovitch M, Doyle RL. Insulin resistance in pulmonary arterial hypertension. Eur Respir J. 2009; 33:318-24. doi: 10.1183/09031936.00000508.

54. Heresi GA, Aytekin M, Newman J, DiDonato J, Dweik RA. Plasma levels of high-density lipoprotein cholesterol and outcomes in pulmonary arterial hypertension. Am J Respir Crit Care Med. 2010; 182:661-8. doi: 10.1164/ rccm.201001-0007OC.

55. Hautefort A, Girerd B, Montani D, Cohen-Kaminsky S, Price L, Lambrecht BN, Humbert M, Perros F. T-helper 17 cell polarization in pulmonary arterial hypertension. Chest. 2015; 147:1610-20. doi: 10.1378/chest.14-1678.

56. Cracowski JL, Labarère J, Renversez JC, Degano B, Chabot F, Humbert M. Plasma levels of high-density lipoprotein cholesterol are not associated with survival in pulmonary arterial hypertension. Am J Respir Crit Care Med. 2012; 186:107; author reply 107-108. doi: 10.1164/ ajrccm.186.1.107.

57. Larsen CM, McCully RB, Murphy JG, Kushwaha SS, Frantz RP, Kane GC. Usefulness of High-Density Lipoprotein Cholesterol to Predict Survival in Pulmonary Arterial Hypertension. Am J Cardiol. 2016; 118:292-7. doi: 10.1016/j.amjcard.2016.04.028.

58. Zhao QH, Peng FH, Wei H, He J, Chen FD, Di RM, Jiang X, Jiang R, Chen YJ, Heresi GA, Jing ZC. Serum highdensity lipoprotein cholesterol levels as a prognostic indicator in patients with idiopathic pulmonary arterial hypertension. Am J Cardiol. 2012; 110:433-9. doi: 10.1016/j.amjcard.2012.03.042.

59. Jacquin S, Rincheval V, Mignotte B, Richard S, Humbert M, Mercier O, Londoño-Vallejo A, Fadel E, Eddahibi S. Inactivation of p53 Is Sufficient to Induce Development of Pulmonary Hypertension in Rats. PLoS ONE. 2015; 10: e0131940. doi: 10.1371/journal.pone.0131940.

60. Mouraret N, Marcos E, Abid S, Gary-Bobo G, Saker M, Houssaini A, Dubois-Rande JL, Boyer L, Boczkowski J, Derumeaux G, Amsellem V, Adnot S. Activation of lung p53 by Nutlin-3a prevents and reverses experimental pulmonary hypertension. Circulation. 2013; 127:1664-76. doi: 10.1161/CIRCULATIONAHA.113.002434.

61. Assadian S, El-Assaad W, Wang XQD, Gannon PO, Barrès V, Latour M, Mes Masson AM, Saad F, Sado Y, Dostie J, Teodoro JG. p53 inhibits angiogenesis by inducing the production of Arresten. Cancer Res. 2012; 72:1270-9. doi: 10.1158/0008-5472.CAN-11-2348.

62. Potus F, Malenfant S, Graydon C, Mainguy V, Tremblay È, Breuils-Bonnet S, Ribeiro F, Porlier A, Maltais F, Bonnet S, Provencher S. Impaired angiogenesis and peripheral muscle microcirculation loss contribute to exercise intolerance in pulmonary arterial hypertension. Am J Respir Crit Care Med. 2014; 190:318-28. doi: 10.1164/rccm.201402-0383OC.

63. Manders E, Rain S, Bogaard HJ, Handoko ML, Stienen GJM, Vonk-Noordegraaf A, Ottenheijm CAC, de Man FS. The striated muscles in pulmonary arterial hypertension: adaptations beyond the right ventricle. Eur Respir J. 2015; 46:832-42. doi: 10.1183/13993003.02052-2014.

64. Meek DW. Regulation of the p53 response and its relationship to cancer. Biochem J. 2015; 469:325-46. doi: 10.1042/BJ20150517. 
65. Hoffmann J, Wilhelm J, Olschewski A, Kwapiszewska G. Microarray analysis in pulmonary hypertension. Eur Respir J. 2016; 48:229-41. doi: 10.1183/13993003.02030-2015.

66. Rhodes CJ, Im H, Cao A, Hennigs JK, Wang L, Sa S, Chen PI, Nickel NP, Miyagawa K, Hopper RK, Tojais NF, Li $\mathrm{CG}, \mathrm{Gu} \mathrm{M}$, et al. RNA Sequencing Analysis Detection of a Novel Pathway of Endothelial Dysfunction in Pulmonary Arterial Hypertension. Am J Respir Crit Care Med. 2015; 192:356-66. doi: 10.1164/rccm.201408-15280C.

67. Tang LL, Zhang LY, Lao LJ, Hu QY, Gu WZ, Fu LC, $\mathrm{Du} \mathrm{LZ}$. Epigenetics of Notch1 regulation in pulmonary microvascular rarefaction following extrauterine growth restriction. Respir Res. 2015; 16: 66. doi: 10.1186/s12931015-0226-2.

68. Irizarry RA, Ladd-Acosta C, Wen B, Wu Z, Montano C, Onyango P, Cui H, Gabo K, Rongione M, Webster M, Ji H, Potash JB, Sabunciyan S, et al. The human colon cancer methylome shows similar hypo- and hypermethylation at conserved tissue-specific $\mathrm{CpG}$ island shores. Nat Genet. 2009; 41:178-86. doi: 10.1038/ng.298.

69. Klug M, Heinz S, Gebhard C, Schwarzfischer L, Krause SW, Andreesen R, Rehli M. Active DNA demethylation in human postmitotic cells correlates with activating histone modifications, but not transcription levels. Genome Biol. 2010; 11: R63. doi: 10.1186/gb-2010-11-6-r63.

70. Choi JK. Contrasting chromatin organization of $\mathrm{CpG}$ islands and exons in the human genome. Genome Biol. 2010; 11: R70. doi: 10.1186/gb-2010-11-7-r70.

71. Dudziec E, Miah S, Choudhry HM, Owen HC, Blizard S, Glover M, Hamdy FC, Catto JW. Hypermethylation of $\mathrm{CpG}$ islands and shores around specific microRNAs and mirtrons is associated with the phenotype and presence of bladder cancer. Clin Cancer Res. 2011; 17:1287-96. doi: 10.1158/1078-0432.CCR-10-2017.

72. Ushijima T. Epigenetic field for cancerization. J Biochem Mol Biol. 2007; 40:142-50.

73. Baba Y, Ishimoto T, Kurashige J, Iwatsuki M, Sakamoto Y, Yoshida N, Watanabe M, Baba H. Epigenetic field cancerization in gastrointestinal cancers. Cancer Lett. 2016; 375:360-6. doi: 10.1016/j.canlet.2016.03.009.

74. El Kasmi KC, Pugliese SC, Riddle SR, Poth JM, Anderson AL, Frid MG, Li M, Pullamsetti SS, Savai R, Nagel MA, Fini MA, Graham BB, Tuder RM, et al. Adventitial fibroblasts induce a distinct proinflammatory/ profibrotic macrophage phenotype in pulmonary hypertension. J Immunol. 2014; 193:597-609. doi: 10.4049/ jimmunol.1303048.

75. Hayashi $\mathrm{T}$, Kotani H, Yamaguchi $\mathrm{T}$, Taguchi K, Iida M, Ina K, Maeda M, Kuzuya M, Hattori Y, Ignarro LJ. Endothelial cellular senescence is inhibited by liver $\mathrm{X}$ receptor activation with an additional mechanism for its atheroprotection in diabetes. Proc Natl Acad Sci USA. 2014; 111:1168-73. doi: 10.1073/pnas.1322153111.

76. Perros F, Ranchoux B, Izikki M, Bentebbal S, Happé C, Antigny F, Jourdon P, Dorfmüller P, Lecerf F, Fadel E,
Simonneau G, Humbert M, Bogaard HJ, et al. Nebivolol for improving endothelial dysfunction, pulmonary vascular remodeling, and right heart function in pulmonary hypertension. J Am Coll Cardiol. 2015; 65:668-80. doi: 10.1016/j.jacc.2014.11.050.

77. Terasaka N, Hiroshima A, Koieyama T, Ubukata N, Morikawa Y, Nakai D, Inaba T. T-0901317, a synthetic liver $\mathrm{X}$ receptor ligand, inhibits development of atherosclerosis in LDL receptor-deficient mice. FEBS Lett. 2003; 536:6-11.

78. Tsai HC, Baylin SB. Cancer epigenetics: linking basic biology to clinical medicine. Cell Res. 2011; 21:502-17. doi: 10.1038/cr.2011.24.

79. Preussner J, Bayer J, Kuenne C, Looso M. ADMIRE: analysis and visualization of differential methylation in genomic regions using the Infinium HumanMethylation450 Assay. Epigenetics Chromatin. 2015; 8: 51. doi: 10.1186/ s13072-015-0045-1.

80. Aryee MJ, Jaffe AE, Corrada-Bravo H, Ladd-Acosta C, Feinberg AP, Hansen KD, Irizarry RA. Minfi: a flexible and comprehensive Bioconductor package for the analysis of Infinium DNA methylation microarrays. Bioinformatics. 2014; 30:1363-9. doi: 10.1093/bioinformatics/btu049.

81. Harrow J, Frankish A, Gonzalez JM, Tapanari E, Diekhans M, Kokocinski F, Aken BL, Barrell D, Zadissa A, Searle S, Barnes I, Bignell A, Boychenko V, et al. GENCODE: the reference human genome annotation for The ENCODE Project. Genome Res. 2012; 22:1760-74. doi: 10.1101/gr.135350.111.

82. Pedersen BS, Schwartz DA, Yang IV, Kechris KJ. Comb-p: software for combining, analyzing, grouping and correcting spatially correlated $P$-values. Bioinformatics. 2012; 28:2986-8. doi: 10.1093/bioinformatics/bts545.

83. Tan CM, Chen EY, Dannenfelser R, Clark NR, Ma'ayan A. Network2Canvas: network visualization on a canvas with enrichment analysis. Bioinformatics. 2013; 29:1872-8. doi: 10.1093/bioinformatics/btt319.

84. Thorvaldsdóttir H, Robinson JT, Mesirov JP. Integrative Genomics Viewer (IGV): high-performance genomics data visualization and exploration. Brief Bioinformatics. 2013; 14:178-92. doi: 10.1093/bib/bbs017.

85. Chaumais MC, Ranchoux B, Montani D, Dorfmüller P, Tu L, Lecerf F, Raymond N, Guignabert C, Price L, Simonneau G, Cohen-Kaminsky S, Humbert M, Perros F. N-acetylcysteine improves established monocrotalineinduced pulmonary hypertension in rats. Respir Res. 2014; 15: 65. doi: 10.1186/1465-9921-15-65.

86. Rajkumar R, Konishi K, Richards TJ, Ishizawar DC, Wiechert AC, Kaminski N, Ahmad F. Genomewide RNA expression profiling in lung identifies distinct signatures in idiopathic pulmonary arterial hypertension and secondary pulmonary hypertension. Am J Physiol Heart Circ Physiol. 2010; 298: H1235-1248. doi: 10.1152/ajpheart.00254.2009. 